\title{
Article
}

\section{An update on developments in medical education in response to the COVID-19 pandemic: A BEME scoping review: BEME Guide No. 64}

Daniel, Michelle, Gordon, Morris, Patricio, Madalena, Hider, Ahmad, Pawlik, Cameron, Bhagdev, Rhea, Ahmad, Shoaib, Alston, Sebastian, Park, Sophie, Pawlikowska, Teresa, Rees, Eliot, Doyle, Andrea Jane, Pammi, Mohan, Thammasitboon, Satid, Haas, Mary, Peterson, William, Lew, Madelyn, Khamees, Deena, Spadafore, Maxwell, Clarke, Nicola and Stojan, Jennifer

Available at http://clok.uclan.ac.uk/36617/

Daniel, Michelle, Gordon, Morris ORCID: 0000-0002-1216-5158, Patricio, Madalena, Hider, Ahmad, Pawlik, Cameron, Bhagdev, Rhea, Ahmad, Shoaib, Alston, Sebastian, Park, Sophie et al (2021) An update on developments in medical education in response to the COVID-19 pandemic: A BEME scoping review: BEME Guide No. 64. Medical Teacher, 43 (3). pp. 253-271. ISSN 0142$159 X$

It is advisable to refer to the publisher's version if you intend to cite from the work. http://dx.doi.org/10.1080/0142159x.2020.1864310

For more information about UCLan's research in this area go to http://www.uclan.ac.uk/researchgroups/ and search for <name of research Group>.

For information about Research generally at UCLan please go to http://www.uclan.ac.uk/research/

All outputs in CLoK are protected by Intellectual Property Rights law, including Copyright law. Copyright, IPR and Moral Rights for the works on this site are retained by the individual authors and/or other copyright owners. Terms and conditions for use of this material are defined in the policies page. 


\section{An update on developments in medical education in response to the COVID-19 pandemic: A BEME scoping review}

\section{Abstract \\ Background}

COVID-19 has fundamentally altered how education is delivered. Gordon et al. previously conducted a review of medical education developments in response to COVID-19, however, the field has rapidly evolved in the ensuing months. This scoping review aims to map the extent, range and nature of subsequent developments, summarizing the expanding evidence base and identifying areas for future research.

\section{Methods}

The authors followed the five stages of a scoping review outlined by Arskey and O'Malley. Four online databases and MedEdPublish were searched. Two authors independently screened titles, abstracts and full texts. Included articles described developments in medical education deployed in response to COVID-19 and reported outcomes. Data extraction was completed by two authors and synthesized into a variety of maps and charts.

\section{Results}

One hundred twenty-seven articles were included: 104 were from North America, Asia and Europe; 51 were undergraduate, 41 graduate, 22 continuing medical education, and 13 mixed; 35 were implemented by universities, 75 by academic hospitals, and 17 by organizations or collaborations. The focus of developments included pivoting to online learning $(n=58)$, simulation $(\mathrm{n}=24)$, assessment $(\mathrm{n}=11)$, well-being $(\mathrm{n}=8)$, telehealth $(\mathrm{n}=5)$, clinical service 
reconfigurations $(n=4)$, interviews $(n=4)$, service provision $(n=2)$, faculty development $(n=2)$ and other $(n=9)$. The most common Kirkpatrick outcome reported was Level 1, however, a number of studies reported $2 \mathrm{a}$ or $2 \mathrm{~b}$. A few described Levels 3, 4a, $4 \mathrm{~b}$ or other outcomes (e.g. quality improvement).

\section{Conclusions}

This scoping review mapped the available literature on developments in medical education in response to COVID-19, summarizing developments and outcomes to serve as a guide for future work. The review highlighted areas of relative strength, as well as several gaps. Numerous articles have been written about remote learning and simulation and these areas are ripe for full systematic reviews. Telehealth, interviews and faculty development were lacking and need urgent attention.

\section{Practice Points}

- Most developments to date focused on pivoting to online learning and simulation, making these areas well poised for full systematic reviews.

- Research on telehealth, interviews and faculty development to teach in remote environments was lacking and urgently needed.

- Several exemplary articles demonstrated the power of collaboration, highlighting opportunities for enhanced cooperation in medical education in the future.

\section{Keywords}

Best evidence medical education, undergraduate, postgraduate, continuing 


\section{Background}

The novel coronavirus disease (COVID-19) has profoundly impacted the way medical education is delivered across the continuum. The need for physical distancing to limit spread of the virus, concerns about the supply of personal protective equipment (PPE), risks of contracting the virus in the clinical environment, and stressors on faculty and trainee well-being have created significant challenges. The impact of these disruptions is likely to be far-reaching, as students have reported a reduction in confidence and preparedness levels (Choi et al. 2020), and some medical schools have even graduated students early to be able to augment the workforce (Glenn 2020). Additionally, students have reported that their disrupted training experiences during the pandemic are likely to impact their specialty selection (Byrnes et al. 2020). Disruptions in clinical experiences have also forced accreditation bodies to adapt requirements for graduate medical education programs (Nasca 2020).

Despite many challenges, the COVID-19 pandemic has also highlighted several opportunities, including enhanced global cooperation in higher education and research (Buitendijk et al. 2020), engaging students and trainees as agents of change (Reardon et al. 2020), and embracing technology and telehealth as powerful tools for both teaching and patient care (Keswani et al. 2020, Pears et al. 2020). As educators have rapidly employed educational developments to mitigate disruptions and harness opportunity, journals have fast-tracked peer review and publication in order to more rapidly disseminate findings to the broader community of educators facing shared challenges. Busy educators now find themselves juggling the maintenance of educational programs amidst the disruption with need to stay abreast of the high volume of emerging literature. 
Prior reviews have attempted to capture the breadth and depth of rapid medical education developments in response to COVID-19 and thereby provide educators with easily referenced resources summarizing work to date. Dedeilia et al. (2020) performed an early review through 18 April 2020 that included letters, commentaries, editorials and perspectives due to the paucity of studies with empiric data or descriptions of implemented innovations. In order to capture the subsequent increase in the volume and quality of developments that followed, Gordon et al. (2020) conducted a rapid systematic review of articles published from 1 December 2019 through 24 May 2020, but chose to exclude letters, editorials, commentaries, and perspectives. The authors highlighted several areas, including pivoting educational delivery from classroombased learning to virtual spaces, replacing clinical placement-based learning with alternate approaches, and supporting direct patient contact with mitigated risk. Additional areas addressed, albeit less extensively, included training for care of patients with COVID-19, service reconfigurations, assessment, well-being, faculty development and admissions. The authors noted a scarcity of articles meeting criteria for education quality, and lack of detail or evaluation data. The majority of articles reviewed (67\%) did not offer any outcome data, and those that did largely reported Kirpatrick Level 1 (satisfaction / reaction). Several of the articles reviewed did, however, explicitly state future plans for evaluation of educational effectiveness. Intentions for future work thus indicated a need for short-term updates as the field was rapidly evolving. Since this review, a flood of additional developments has continued to emerge in the literature.

The aim of the current scoping review is to map the extent, range and nature of medical education developments in response to the COVID-19 pandemic since our prior review; to 
summarize and disseminate current research findings of this rapidly expanding evidence base; to identify gaps in the existing literature for future research; and to determine areas of focus for future systematic reviews.

\section{Methods}

Similar to our prior review, this scoping review was conducted in a rapid timeframe ( $\sim 8$ weeks from inception to completion). The speed with which the review was conducted, however, did not compromise rigor or systematicity, which we employed from the search strategy to the synthesis (Gordon et al. 2019a). The work was guided by our previously published framework (Gordon et al. 2020) and the model for scoping reviews described by Arksey and O'Malley (2005). A study protocol was drafted a priori and posted on the BEME website. The reporting aligns with the overarching requirements in the STORIES (STructured apprOach to the Reporting In healthcare education of Evidence Synthesis) statement (Gordon and Gibbs 2014) and BEME guidance (Hammick et al. 2010), as there is no clear framework for reporting scoping reviews in the field.

The five stages of a scoping review were followed (Arksey and O'Malley 2005):

Stage 1: identifying the research aims / questions (as stated above)

Stage 2: identifying relevant studies

Stage 3: study selection

Stage 4: charting the data

Stage 5: collating, summarizing and reporting the results 


\section{Stage 2: identifying relevant studies}

Aligning with the procedures in our prior review (Gordon et al. 2020), we electronically searched four databases (MEDLINE, EMBASE, CINAHL and PsychINFO). These 4 databases were selected as they contain almost all the journals that publish on medical education. We searched PubMed from May 1, 2020 - September 09, 2020, allowing for three weeks of overlap in our search dates with the prior review to ensure no primary studies were missed. We hand searched MedEdPublish for the same time period. We searched the remaining databases from January 1 , 2020 to September 19, 2020, as delineating by month in these databases wasn't possible. Studies that were included in our previous systematic review were removed.

After consultation with a librarian, we updated our original search strategy (Gordon et al. 2020) to enhance specificity and to better comply with current searching and reporting standards. We utilized the Accelerator Polyglot search translation tool to develop the searches (Clark et al. 2020). The full search strategy can be found in Appendix 1. Hand-searching of references of the primary papers was not conducted, as the author team was concerned speed would be compromised for minimal added benefit given the short time frame from the onset of the pandemic.

Deduplication was conducted using Endnote (Bramer et al. 2016.) Retrieved citations were then uploaded in DistillerSR (Evidence Partners, Ottawa, Ontario, Canada), an online data management system for performing systematic reviews. Titles and abstracts were independently screened by two authors against an initial set of inclusion and exclusion criteria (see below). 
Inter-rater reliability was calculated using Cohen's Kappa. Full texts were retrieved and independently reviewed by two authors against a revised set of inclusion and exclusion criteria based on the findings of the initial screen. The full text screening form appears in Appendix 2. Discrepancies at all stages were resolved through discussion, including a third author as needed, until consensus was reached.

\section{Stage 3: study selection}

We were initially uncertain if the evidence base would have improved sufficiently from our prior review (Gordon et al. 2020) to require outcomes as an inclusion criteria. Thus, we planned to revise our inclusion criteria to include outcomes after the initial screening if the evidence base was sufficient. This practice aligns with procedures outlined for scoping reviews, which allows for post hoc revision of criteria, as authors become more familiar with the evidence base (Levac et al. 2010).

Our initial inclusion criteria were as follows:

- Studies that described developments in medical education explicitly deployed in response to COVID-19.

- Studies in undergraduate, graduate or continuing medical education.

- Studies with medical students, residents, fellows, or physicians.

- Studies in any language.

After initial screening, we added the following inclusion criteria: 
- Studies that consider Kirkpatrick's outcomes (Level 1: Reaction, Level 2: Learning, Level 3: Behavioral Change, Level 4: Organizational Performance) (Kirkpatrick 2016) OR other outcomes (e.g., quality improvement).

Our exclusion criteria were as follows:

- Opinion pieces, commentaries, editorials, perspectives, calls for change, needs assessments and other studies where no actual development had been deployed.

- Studies that described the development as a minor part of a larger package of planned measures.

- Studies that only have other healthcare professionals (i.e. other than medics)

- Studies that were included in our previous systematic review from December 1^, 2019 May 24", 2020

\section{Stage 4: charting the data}

We developed a data-charting form modified from the form used in our prior review (Gordon et al. 2020) to align with the aims of this scoping review. The form was loaded into Google Sheets to facilitate sharing of data. A team meeting was held to ensure shared understanding of terms, prior to article distribution. Primary studies were assigned to author pairs based on the focus of the development. This facilitated author teams developing a content area of expertise for reporting of results. Each author team piloted the data extraction form on one of their primary studies prior to conducting their independent reviews. At least one author in each team had participated in the prior review, further ensuring a shared mental model for data charting. All 
discrepancies were resolved through discussion or involvement of the lead author. Quality assessments were not undertaken as these are not frequent in scoping reviews (Arksey and O’Malley 2005).

Data extracted included:

- Article identifiers (author(s), month of publication)

- Context

- Geographic origin of development and local COVID-19 specific details

- Participants (both type and number), level of medical education (e.g. undergraduate medical education (UME), graduate medical education (GME), continuing medical education (CME) or mixed)

- Setting or institution responsible for educational delivery (e.g., university, academic hospital)

- Medical specialty if applicable

- Description of intervention

- Primary focus of the development

- Stated purpose of deployment (i.e. what problem was addressed?)

- Brief summary of development

- Further description of development with any links to materials

- Theoretical models or conceptual frameworks

- Resources (details of cost / time / other resources)

- Intervention outcome(s) (modified Kirkpatrick outcome level or similar (Barr et al. 2008)) 
- Level 1 participant reaction

- Level 2a changes in attitudes; Level $2 \mathrm{~b}$ changes in knowledge or skills

- Level 3 behavioral change

- Level 4a change in organizational practice; Level $4 \mathrm{~b}$ change in clinical outcomes

○ Other outcomes (e.g. quality improvements, policy changes, checklist development, or other impacts)

- Summary of results

- Lessons learnt

- Key points from discussion

- Summary of conclusion

- What future research is indicated either implicitly or explicitly

\section{Stage 5: collating, summarizing and reporting the results}

Utilizing data from the Google Sheet, the authors collated the data into a number of tables and figures for easy visualization, to provide a map of the current evidence base. After charting the large volume of data, we also produced a narrative account of our findings that considers the extent and range of developments included in the review, as well as the outcomes assessed. We identified areas of educational developments that have been thoroughly addressed since the onset of the pandemic and those where a paucity of research exists. We also suggested areas for future primary and secondary studies (i.e. systematic reviews). 


\section{Results}

A total of 12,627 records were identified through database searching, and an additional 31 by hand searching MedEdPublish. After deduplication, 7,237 records remained. After title and abstract screening, 6,752 records were excluded. Four-hundred-eighty-five studies underwent full text screening and 358 were excluded. Inter-rater reliability at the screening phase was $\kappa=0.91$, suggesting excellent alignment. The primary reasons articles got excluded were the full text was unavailable $(n=2)$; the development was not in medical education, or not explicitly deployed in response to COVID $19(\mathrm{n}=53)$; the participants did not include medical students, residents, fellows or physicians $(n=9)$; the primary study was an opinion piece, commentary, editorial, perspective, call for change, needs assessment or survey, or other study where no actual development was deployed $(n=123)$; the development was a minor part of a larger package $(n=$ 5); or no outcomes, Kirkpatrick's or otherwise, were reported ( $n=166)$. One hundred twentyseven studies were included in the final analysis. The flow diagram for article identification is shown in Figure 1 (PRISMA 2015).

\section{[INSERT FIGURE 1 NEAR HERE]}

Table 1 provides a brief summary of all included primary studies, in addition to other key data. Please note that due to the large number of articles included in this scoping review, we cannot not list all the studies by author last name when presenting the results. We have chosen to cite exemplars that highlight our findings. The complete list of studies can be identified via 
referencing the appropriate columns in Table 1. Figure 2 provides a graphic summary of the review.

\section{[INSERT TABLE 1 AND FIGURE 2 NEAR HERE]}

\section{Month of Publication}

Our last review ended May 24, 2020. This review, with enhanced search criteria, picked up 4 additional articles from April missed by the first review, and 17 articles from May. The latter are likely representative of articles that were in process when the last search was run or from the last week of May. June, July and August saw similar numbers of publications, with 32, 30, and 31 articles respectively. Thirteen articles were identified in September, but our search likely missed articles published later in the month due to the dates on which they were run. Overall the numbers demonstrate a continued acceleration of publications in medical education related to COVID since our last review (Gordon et al. 2020), despite the fact this review had more stringent inclusion criteria, namely reporting of outcomes.

\section{Geographic origin of studies and local COVID-19 details}

Table 2 and Figure 2 show the geographic origins of the included studies according to level of medical education (UME, GME, CME, or Mixed). Fifty-nine studies (46.5\%) were conducted in the United States and five (3.9\%) in Canada, for a total of sixty-four in North America. Four studies (3.1\%) were conducted in South America, twenty (15.7\%) in Europe, eleven (8.7\%) in the Middle East, one (0.8\%) in Africa, twenty (15.8\%) in Asia, and two (1.6\%) in Oceania (e.g., Australia and New Zealand). An additional 5 studies (3.9\%) represented international 
collaborations, which does not represent a significant increase in collaborative efforts compared to the prior review (Gordon et al. 2020), despite the elapsed time.

\section{[INSERT TABLE 1 NEAR HERE]}

Local COVID-19 conditions were well summarized by Sa Couto and Nicolau (2020):

"Throughout the globe, universities (were) closed and classes suspended, with recommendations of prophylactic confinement to all not involved in patient care or first-need services. Alternatives to face-to-face classes rapidly emerged and telecommunication platforms (were) the new classrooms." Multiple authors described national authorities or regulatory bodies that called for the cessation of in-person activities. Several articles described the Association of American Medical Colleges (AAMC) recommendation to cancel all pre-clinical classes and in-person experiences, including core clinical clerkships and electives to protect learners and preserve personal protective equipment (PPE). Countries (e.g., United Kingdom, United Arab Emirates, Saudi Arabia, India, and Lebanon) shelter-in-place orders, mandatory lockdowns and curfews were all described. Medical students in Hong Kong were reportedly barred from entering the hospital. Graduate trainees had more variable restrictions on training described. In-person didactic activities were halted. The cessation of elective procedures and the impact of altered patient behaviors on case volume was noted to have the greatest impact on skills training. 


\section{Level of medical education, institutional setting, number of participants, medical}

specialty

Table 3 and Figure 2 map the number of studies by level of education and institutional setting. Fifty-one studies (40.2\%) described developments in undergraduate medical education (UME), forty-one (32.3\%) in graduate medical education, and twenty-two (17.3\%) in continuing medical education. Thirteen studies (10.2\%) reported multiple levels of learners. Thirty-five studies (27.5\%) were conducted in universities, seventy-five (59.1\%) in academic hospitals, ten (7.9\%) as part of collaborations and seven (5.5\%) were conducted by other groups such as state or national organizations. UME activities were largely university based, though a number of UME activities were administered by academic hospitals, which is not surprising given that pre-clinical and clinical learning activities are typically shared across sites. GME and CME activities were mostly run by academic hospitals, and to a much lesser extent, collaborations or national organizations. Overall, there remains a relative paucity of regionally and nationally organized efforts and collaborative work, considering we are globally facing similar challenges.

\section{[INSERT TABLE 3 NEAR HERE]}

The number of participants in each study ranged from 5 (Bautista et al. 2020, Gallardo et al.2020) to 30,000 (Dubé, et al.). Approximately 1/3 of studies had more than 100 participants, though the majority of studies had less than 100 participants, and many did not report a precise number of learners. 
Table 4 and Figure 2 chart the disciplines or medical specialties represented by the studies and educational level. The data is also graphically summarized in Figure 2. For twenty-one (16.5\%) of the UME studies, a specialty is not described. Most core clerkships are represented by at least one study, though family medicine and psychiatry are notable gaps. General surgery and the surgical subspecialties are the most represented (eight studies, combined). Specialties are described for nearly all of the GME and CME studies, reflective of the differentiation that occurs at those levels. Again, the surgical specialties are the most represented in GME with fourteen studies. Multi-professional activities are most well-represented within CME with eleven studies, and to a lesser degree in GME and Mixed (five and four, respectively). These studies are mostly simulation-based, aimed at helping practicing clinicians care for patients with COVID-19.

\section{[ INSERT TABLE 4 NEAR HERE]}

\section{Summary of educational developments}

One-hundred twenty-seven educational developments were described. Table 5 and Figure 2 map the focus of the development to the level of education (UME, GME, CME, Mixed). The focus of the developments, in descending order by representation included:

- Pivoting to online learning (58 primary studies, $45.7 \%$ )

- Simulation or training for treating patients with COVID-19 (24 primary studies, 18.9\%)

- Assessment (11 primary studies, $8.7 \%)$

- Wellbeing, mental health or learner support (8 primary studies, $6.3 \%$ )

- $\quad$ Telehealth (5 primary studies, $3.9 \%$ )

- Clinical service reconfigurations to support the response to COVID-19 (4 primary studies, $3.1 \%$ ) 
- Interviews for admission to medical school, selection to residency (4 primary studies, $3.1 \%)$

- Service provision (2 primary studies, $1.6 \%$ )

- Faculty or professional development (2 primary studies, $1.6 \%$ )

- Other or multiple areas of focus (9 primary studies, $7.1 \%)$

The types of studies were not evenly distributed across the educational continuum. A majority or near majority of the UME and GME primary studies were in the pivot to online learning category, with $31 / 51$ or $60.8 \%$ of all UME studies and $20 / 41$ or $48.8 \%$ of all GME studies. Similarly, a majority or near majority of CME and mixed primary studies were in the simulation or training to treat patients with COVID-19 category, with 14/22 or 63.6\% of all CME studies and $6 / 13$ or $46.2 \%$ of all mixed studies. There was a complete paucity of articles on telehealth, interviews, faculty development, clinical service reconfiguration and service provision.

\section{[ INSERT TABLE 5 NEAR HERE]}

\section{Pivoting to online learning}

Nearly half of the developments identified in this review discussed a transition from in-person, face-to-face instruction to online learning: Fifty-eight articles (45.7\%) described the pivot to online learning as the primary focus of their development, with an additional five articles (3.9\%) describing a pivot as a part of their intervention. Of these, thirty articles (23.6\%) described exclusively synchronous learning (i.e., students and instructors gather in real time, providing opportunities for interaction and feedback). Only four articles (2.4\%) reported exclusively asynchronous learning (i.e., instructors prepare materials in advance and students access them at 
their own pace.) An additional twenty-nine articles (22.8\%) described developments that incorporated components of both synchronous and asynchronous learning.

Many articles highlighted the conversion of didactic sessions to synchronous video conferenced lectures on a variety of platforms (e.g., Zoom (the most popular), Microsoft Teams, WebEx, Skype for business). For synchronous sessions, several strategies were used to foster learner engagement and interaction, including the chat box, Breakout rooms, polling software, virtual whiteboards, annotate functions, quizzes and games (e.g., Kahoot, Jeopardy). Social media platforms (e.g., WhatsApp, Slack, Instagram, Twitter) were utilized in conjunction to promote dialogue, concurrently or after sessions. A number of active learning pedagogies were also tried, including case-based learning (CBL) (Steehler et al. 2020), problem-based learning (PBL; Coiado et al. 2020), team-based learning (TBL) (Jumat et al. 2020), and flipped classroom (Beer et al. 2020, Naidoo et al. 2020, Roy et al. 2020). For pre-recorded lectures and other asynchronous materials, a number of learning management sites were used to facilitate access (e.g., Canvas, Google Classroom).

Evaluations of both synchronous and asynchronous approaches were mixed. (See table 1, summary of results and lessons learnt columns.) Many learners agreed that the online formats were acceptable means of acquiring theoretical or content knowledge, however, teaching procedural, lab-based or clinical skills was more challenging (e.g., Joseph et. al. 2020, Khalil et. al. 2020, Shahrvini et al. 2020). Advantages to online learning cited included increased attendance, flexibility (access anytime, anywhere (e.g., Sud et al. 2020) and convenience / ability to work from home, less time spent travelling, self-pacing, time for reflection, multimedia 
learning and scalability. A few studies leveraged the disruptions imposed by the pandemic as an opportunity to break out from traditional boundaries. Regional, national and international collaborations emerged (e.g., Balakrishna et al. 2020, Beer et al. 2020, Rose et al. 2020) allowing more educators to contribute and experts or those with different perspectives to be accessed, expanding local capacity to continue education during the crisis. Disadvantages of online learning cited included lack of social connections and interpersonal interactions with faculty and peers, passive participation, distractions of the online environment, communication challenges, “Zoom fatigue" (e.g., Lieberman et al. 2020), and cyber threats (e.g., "Zoom bombing” (Rasouli et al. 2020)) or information security issues. Discordance was seen across studies regarding learner engagement, participation and interactivity, with some studies describing "more", the "same" or "less" in the online environment (e.g., Coiado et al.2020, Jones et al. 2020, Evans et al. 2020, Wlodarczyk et al. 2020). This likely reflects the different levels of active or selfdirected learning employed in each development. Poor internet connectivity (i.e., issues with speed and bandwidth), lags in audiovisuals, poor image resolution or voice quality, and technical issues with hardware and software were frequently cited additional challenges, that can be exacerbated by inequities in access (e.g., Tang et al. 2020). From the subset of articles that evaluated faculty perspectives, faculty noted the significant additional level of faculty and administrative effort required to develop and implement remote learning and noted an urgent need for additional training, both in regards to technical tools, as well as effective teaching methods or best practices underpinned by theories. Notably, despite this expressed need, we found no faculty development activities focused on online learning in this subset of articles, and very few articles reported on the educational theories underpinning their work. Only a few 
articles mentioned multimedia, social constructivism and blended learning theories (e.g., Naidoo et al. 2020, Jumat et al. 2020).

A large number of developments focused on mere replacing previously classroom-based activities (e.g., lectures, small groups, CBL, TBL, PBL, flipped classroom) to the remote online environment to address immediate needs. These developments tended to be focused on enhancing medical knowledge through a variety of formats. Only a handful of articles described innovative approaches to transform face-to-face learning to online learning. One article (O’Connell et al. 2020) developed a game based off the television series "So You Think You Can Dance?”, involving several rounds of rapid-fire questions, as teams compete and are eliminated into a final "face-off". Another article (Clemmons et al. 2020) described standing up a new course focused on the COVID-19 pandemic, to address rapidly evolving basic, clinical and health systems science topics, including public health, and health equity. A few articles discussed communication skills training through video conferencing using actors or standardized patients (Carroll et al. 2020, Mohos et.al 2020, Shahrvini et al. 2020) and role plays (Newcomb et al. 2020). Three studies addressed oral case presentation skill development using virtual cases and video presentations (Geha \& Dhaliwal 2020, Krawiec \& Myers 2020) or remote participation in ward rounds (Pennell et al. 2020). Several studies described innovations for distanced procedural skill development with feedback, including surgical knot tying,(Co and Chu 2020;) basic suturing (Kuo et al. 2020), corneal repair of porcine eyes utilizing a remote wet lab (Pasricha et al. 2020), microsurgical skills training (Gallardo et al. 2020), laparoscopic skill training (Jarry Trujillo et al. 2020), and ultrasound scanning using a simulator (Singh et al. 2020). 
For continued clinical training in UME and GME, two types of developments identified: 1) remote image or slide review in specialties that do not typically have a direct patient encounter (e.g., pathology and radiology) to simulate "signouts" or "readouts" and 2) integration of remote learners into direct patient encoutners. In Pathology, Evans et al. (2020) and Samueli et al. (2020) used whole slide image repositories, Parker et al. (2020) utilized Pathpresenter, and Tang et al. (2020) used a camera enabled microscope connected to screen-share on Zoom. In Radiology, Gomez et al. (2020) and McRoy et al. 2020 used Pacsbin to enable construction of HIPAA compliant image libraries for remote case review and Matalon et. al (2020) and Recht et al. (2020) engaged in real-time and simulated remote readouts. In Obstetrics and Gynecology, Pennell et al. (2020) obtained patient permission to live-stream ward rounds via video on a mobile phone, allowing learners to participate in the patient interview and clinical decisionmaking. In Neurosurgery, multiple video inputs allowed virtual learners to participate in surgeries remotely, asking real-time questions of the team via Bluetooth headsets. In Otolaryngology, virtual ward rounds were broadcast across the African continent by a collaboration of ear, nose and throat surgeons (Goncalves et al. 2020).

\section{Simulation or training for treating patients with COVID-19}

Twenty-four articles (18.9\%) focused exclusively on simulation or another type of training to support the care of patients during the pandemic. These represented twenty-three developments, as different aspects of the same development were discussed in two articles (Andreae et al. 2020a; Andreae et al. 2020b). One additional article (Carroll et al. 2020) described both a pivot to online learning and a training to help develop serious illness communication skills to facilitate difficult dialogue with patients with COVID-19. All described developments were implemented 
as part of graduate or continuing medical education by either academic hospitals or collaborations. The majority of simulations were multi-disciplinary or multi-professional, reflective of how modern teams deliver care. The focus of trainings included both technical skills (e.g., proper donning and doffing of PPE, procedural skills, effective airway management, cardiopulmonary resuscitation) and non-technical skills (i.e., communication, leadership, teamwork, decision-making, situational awareness). On the whole, these articles tended to delineate resources and costs in greater detail than other developments in this review, facilitating replicability. They also tended to provide detailed descriptions of the simulation scenarios, checklists, or other educational materials. For examples, please see Conrad et al. (2020), figure 1; Andreae et al. (2020b) Tables 1-3; and LoSavio et al. (2020) Figure 1 (tracheostomy protocol) and Figure 5 (instruction script).

Three articles described interventions to train providers to treat patients with COVID-19 that were not simulation based: Suppan et al. (2020) conducted a rigorous, randomized controlled trial to explore the use of a gamified e-learning module to teach proper PPE selection. Despite evidence of effectiveness in teaching knowledge and skills, there was no significant difference in learner satisfaction with the gamified format compared to simply reviewing guidelines. Aluisio et al. (2020) described a curriculum that targeted "trainers of trainees" to rapidly disseminate information to treat patients with COVID-19 in low- and lower-middle income countries. Carroll et al. (2020) modified a pre-existing training to teach serious illness conversations using remote live actors, to address many of the acute challenges of caring for patients with COVID, particularly when resources are scarce. 
Fifteen articles described in-situ training simulations, often with native teams in their "home" work environment which spanned emergency departments, intensive care units, operating rooms, labor and delivery units, general wards, urgent care centers, and diagnostic imaging suites. Many in-situ trainings were dual purposed as simulation-based clinical systems testing (SbCST) as described by Colman et al. (2019). SbCST is a form of quality improvement (QI), used to identify latent safety threats and system inefficiencies, to inform policies and guidelines for the COVID-19 response. Depending on the article, education was either a primary or secondary aim, and many articles described both Kirkpatrick and QI outcomes. A handful of these articles described training very large numbers of individuals: The Alberta Health Service launched an eSIM COVID-19 response team that implemented > 400 simulation trainings for $\sim 30,000$ front line healthcare worker (HCW) over 5 weeks across a geographically distributed Canadian Province (Dubé et al. 2020); Cheung et al. (2020) conducted 101 simulations for 1415 HCW in Hong Kong to standardize hospital-wide practices and minimize exposure to COVID-19; and Buléon et al. (2020) developed and implemented a procedural training curriculum and ensured $1143 \mathrm{HCW}$ in France passed each of 6 stations over a 10 day period.

Five articles focused on conducting simulations in well-equipped simulation labs (Favier et al. 2020; Kesselman et al. 2020; Khan and Kiani 2020; LoSavio et al. 2020; Shi et al. 2020). These simulations were generally used to train smaller numbers of individuals (range 6-44) and had a primary mission of education, as compared to in-situ simulations. Three of these articles focused on conducting highly specific procedures wearing appropriate PPE. Favier et al. (2020) trained otolaryngologists and LoSavio et al. (2020) trained surgeons to perform tracheostomies. 
Kesselman et al. (2020) trained interventional radiologists in endovascular procedures for COVID positive patients.

In the setting of a new pandemic, rapid dissemination of information and training is critically important. A few articles in this category described the exceptional use of previously developed resources (e.g. conceptual models, learning management platforms, collaborative networks). For instance, the Alberta Health System has 650 facilities and 125,000 employees which as part of its pandemic planning had embraced the concept of systems integration, an approach that brings many subsystems together into one, more unified system to enhance safety and quality of care. They were thus poised to launch COVID training in a centrally controlled, yet locally distributed manner. The authors noted that few other health systems in the world would have likely been capable of such a feat (Dubé et al. 2020). Adding to the impressiveness of what they accomplished, they rigorously tracked outcomes, identifying over 2500 systems issues and proactively mitigating them.

\section{Assessment}

Eleven articles $(8.7 \%)$ focused primarily on assessment practices for online and remote assessment. A few other articles mentioned assessments as minor parts of a larger package. The majority of studies occurred in the academic hospital setting, with three in the university setting and one via a national regulatory body (table 1). Eight addressed assessment in medical students, while three addressed assessment strategies for residents or fellows. One dealt with assessment in anatomy, while five others focused on clinical specialties including pediatrics, internal 
medicine, orthopedics and general surgery. Technological platforms utilized included Zoom, WhatsApp, Instagram, ExamHD and Open Notes. (See table 1 for details.)

Seven of the studies focused on evaluating medical knowledge. Amin et al. (2020) involved students in assessment design, having them write case-based questions for a question bank. Gupta et al. (2020) reported a technology enabled anatomy oral exam with no impact on obtained scores. Prigoff et al. (2020) and Sam et al. (2020) reported the use of open book exams with both studies reporting no negative impact on exam results. Gulati et al. (2020) described the use of short clinical scenario multiple choice questions on Instagram which students found both thought provoking and helpful in the consolidation of their learning. Malhotra et al. (2020) and Munshi et al. (2020) used online structured clinical vignettes as an assessment tool, reporting both student and examiner satisfaction with this process. Two of these studies commented on the need to investigate online proctoring (Prigoff et al. 2020, Sam et al. 2020), while Gupta et al. (2020) acknowledged technical limitations regarding proctoring and internet access.

Four of the studies reported assessment of clinical skills. Hannon et al. (2020) described a virtual objective structured clinical examination (OSCE) using Zoom. Although both staff and students appreciated the remote OSCE, students found the narrative physical exam flow to be awkward and preferred in-person exams. Krawiec \& Myers (2020) described the development of a video recorded oral presentation assignment with students being assessed using a patient presentation tool that was not intended for virtual patients. Lara et al. (2020) looked at teleOSCEs via Zoom, finding no differences in mean score or failure rate when compared to live OSCEs. Lawrence, et al. (2020) described the adaption of previously deployed in-person OSCEs to a telemedicine 
environment. While residents expressed enthusiasm for telemedicine training, they had concerns about their preparedness for telemedicine practice.

\section{Wellbeing, mental health or learner support}

Eight articles (6.3\%) primarily focused on well-being, mental health or learner support and one additional article addressed well-being in combination with other areas. These interventions were spread across the continuum ( 3 in UME, 1 in GME, 3 in CME and 1 mixed). Developments addressed provider distress caring for patients with COVID-19, as well as isolation, fear and anxiety associated with the pandemic. Interestingly, three wellbeing interventions involved pediatricians, though in general pediatricians globally have seen fewer sick COVID-19 patients that adult practitioners.

Some of the most successful ideas leveraged existing structures in different ways. Sockalingam et al. (2020) and Steeves-Reece et al. (2020) used an existing collaborative network, the Extension for Community Healthcare Outcomes (ECHO). Project ECHO is set up as a telementoring program for rural frontline clinicians in Oregon. Sockalingham et al. (2020) involved twice weekly sessions with case discussions focused on mindfulness, stress management skills, the humanities and reflections. Steeves-Reece et al. (2020) involved four times weekly sessions featuring community presenters sharing on-the-ground experiences treating patients with COVID-19. These two interventions reached 426 and 737 frontline HCW, respectively. Blankenburg et al. (2020) utilized the membership of the Association of Pediatric Program Directors (APPD) to conduct a prioritized needs assessment. This guided implementation of 
'Virtual Cafes', hourly lunchtime sessions to share educational (36), clinical (11) and well-being (52) innovations, broadcast nationally on Zoom.

A few developments leveraged the humanities to support well-being. Babal et al. (2020) employed a professional storyteller to train teaching faculty to tell stories. Whilst the storytelling sessions were intended to support professional and emotional growth and foster resilience, a few participants found them triggering. The authors noted a more trauma-informed approach may be needed in the future. Chow et al. (2020) used "Cinemeducation", hosting a film screening of The Next Pandemic, a documentary about the severe acute respiratory syndrome (SARS) pandemic. Following the film, faculty trained in guided reflection led small groups through an exploration of sensitive issues (e.g. blame, prejudice, personal and public impact etc.) to improve emotional preparedness for COVID-19.

The remaining studies dealt more directly with support. Mastroianni et al. (2020) paired surgical residents with psychology faculty for mental health support. Hodgson and Hagan (2020) described pastoral care tutors pivoting from face-to-face to virtual support on Microsoft Teams. Rastegar Kazerooni (2020) described using trained senior medical students to help junior students cope with anxiety using stress management techniques, exercise and other coping skills. The near-peer mentoring was carried out via a customized social media platform. Lee et al. (2020) described targeted, 1:1, virtual academic coaching using the Master Adaptive Learner framework. Two academic coaches tracked and analyzed students' performance, with supportive interventions addressing content matters, study habits or learning strategies. 


\section{Telehealth}

Five studies (3.9\%) addressed telehealth. Four studies were in UME and one in GME. These interventions were conducted in a variety of specialties, with most implemented by universities or academic hospitals. Abraham et al. (2020) was able to rapidly incorporate telehealth into an Internal Medicine (IM) clerkship by utilizing existing telehealth modules created prior to the pandemic by the American College of Physicians (https://www.acponline.org/cme-moc/onlinelearning-center/telemedicine-a-practical-guide-for-incorporation-into-your-practice.) After completing the modules, students participated in a weekly telehealth clinic, allowing for ongoing, safe and meaningful patient care. Bautista et al. (2020) piloted an interprofessional rotation for five pharmacy and medical students, wherein learners engaged in collaborative outreach to vulnerable patients via telehealth. The pilot was well received. Long-term evaluation will be crucial as the innovation addressed a number of key learning outcomes (e.g., communication, teamwork, interprofessional practice, patient centeredness and health inequalities). Chandra et al. (2020) engaged medical students in follow ups after discharge from the emergency department using a script and a checklist, with faculty precepting remotely. Tsang et al. (2020) observed learners conducting remote neurologic histories and exams followed by debriefs with faculty preceptors. Huffman et al. (2020) focused on continued training of pediatric fellows. Faculty and fellows would meet for a pre-brief, then the fellow would lead the telehealth encounter with the faculty observing. This was followed by a debrief. Faculty and learners appreciated the intensity of supervision, rich feedback, and observation of other skills. Faculty worried about loss of autonomy and heightened scrutiny, but this was not felt by the fellows. 


\section{Clinical service reconfigurations or early graduation to support the response to}

COVID-19

Four publications (3.1\%) focused primarily on early graduation or clinical service reconfigurations to promote provider safety and meet staffing needs. An additional three articles described clinical service reconfiguration as part of a larger package (i.e., multiple) interventions.

Two articles described the early graduation of medical students to support health systems overwhelmed by persons with COVID-19. Students who had satisfied their training program requirements were approved by the national authorities in Spain to engage in "non-registered" practice supervised by experts (Collado-Boira et al. 2020) or offered limited-licensing for 90 days to work on a completely voluntary basis (Flotte et al. 2020). Student reactions ranged from feeling unprepared and afraid to feeling gratified to contribute. Additional impacts included augmenting system capacity to care for high volume and high acuity patients. Five articles (Astani et al. 2020, Bandi et al. 2020, Dennis et al. 2020, Juprasert et al. 2020, Mastroianni et al. 2020) described either departmental or cross-departmental restructures designed 1) to hold providers in reserve, unexposed to COVID-19, 2) to meet critical staffing / patient care needs, or 3) to ensure various departmental missions (education, clinical care, research) continued despite the pandemic. For example, Astani et al. (2020) described the creation of two teams of radiologists, one image interpretation team and one clinical team redeployed to assist under the clinical supervision of internal medicine and infectious disease doctors. Juprasert et al. 2020 reported on a surgical department restructured to address clinical needs, prioritizing a reserve pool to limit exposures, condensing surgical services, implementing a procedural team, and deploying to support intensive care unit (ICU) expansion. The most remarkable article in this 
group was perhaps Dennis et al. 2020. The authors described the development of a Trainee Pandemic Role Allocation Tool (TPRAT) - (www.covidstaffing.org). This schema categorized trainees according to their core specialties and clinical skill levels to facilitate horizontal care delivery, an institution-wide approach to mobilize the trainee workforce to meet immediate needs. The tool was initially deployed for 1053 trainees at Vanderbilt University, and has been taken up nationally by other hospitals.

\section{Interviews for admission to medical school or selection to residency or fellowship}

Four articles (3.1\%) focused primarily on adapting to a remote interview process due to travel restrictions and logistical difficulties associated with the COVID-19 pandemic. One additional article (Xu et al. 2020), focused on both interviews as well as the pivot to online learning. All of these studies took place in an academic hospital setting and involved surgical or surgical subspecialty programs. From the above papers, three focused on interviewing fellows (Day et al 2020, Molina et al. 2020, Vining et al. 2020) whereas the other two involved pre-interview medical students and residents (Xu et al. 2020, Patel et al. 2020). All studies utilized one or multiple technological platform, with four using Zoom (Patel et al. 2020, Molina et al 20202, Vining et al 2020, Xu et al 2020), two using Web Ex (Day et al. 2020, Xu et al. 2020) and two using google docs/forms (Patel et al. 2020, Molina et al 2020).

Three studies (Day et al. 2020, Molina et al. 2020, Vining et al. 2020) described the process of moving interviews predominately online. These studies reported positive responses to virtual interviews, citing cost and time savings with the elimination of travel. Molina et al. (2020) reported their virtual interview process matched the in-person experience with regards to 
participant perception and Vining et al. (2020) reported the interview flow as "seamless" per the majority of applicants and faculty. Whereas Molina et al. (2020) and Vining et al. (2020) described a completely virtual approach to interviews, Day et al. (2020) described a hybrid approach, with fellows interacting remotely over WebX "moving" from room to room online while two interviewers were physically present in rooms in the hospital. The authors highlighted some unanticipated "social distancing challenges" associated with this hybrid approach for the interviewers, but overall the experience was rated favorably by both applicants and faculty.

$\mathrm{Xu}$ et al. (2020) randomized prospective urology applicants to six programs to give virtual grand rounds. The presentations were meant to allow medical students to express interest in programs and for faculty to begin evaluating them prior to interviews. The authors reported $100 \%$ student satisfaction with the process, but cited problems with standardization across programs in virtual grand rounds delivery. Patel et al. (2020) described an informational webinar designed to educate trainees on the Core Surgical Training selection process for general surgery in the United Kingdom. This study reported over half (55\%) of participants preferred the webinar to face-toface tutorials regarding the interview process, but that participant experience was heavily influenced by internet capabilities.

\section{Service provision}

Only two publications (1.6\%) described developments pertaining to service provision. The first publication described the establishment of a Crisis Management Team CMT) (Ashton, et al. 2020). The CMT identified unmet staffing needs at several regional hospitals in France during the first wave. Leveraging their social networks and leadership skills, they organized and 
dispatched resident volunteers, matching resident skills to local needs. One thousand ninety-two volunteers registered, and 578 were deployed to areas critically impacted by the pandemic, particularly emergency departments (EDs), and ICUs with good effect. The intervention was inspirational in that it showed the potential of the newer generation of clinicians to take charge in times of crisis. The second publication described the integration of medical students into six different service projects to support the health system (Ayoub et al. 2020). Students supported triage efforts in call centers, addressed PPE shortages, assisted with diagnostic testing efforts, discussed care with families separated from hospitalized patients and ensured ongoing access to health appointments for disadvantaged persons. Feedback was strongly positive and highlighted the educational benefits on development of clinical knowledge and communication skills.

\section{Faculty or professional development}

Only two publications (1.6\%) focused on faculty development (i.e. educator training) or professional development in light of COVID-19, though arguably several developments labelled as CME could be categorized as professional development. Buckley (2020) described the implementation of a virtual platform for ongoing faculty development using social networking amongst a cohort of regionally dispersed teachers. The aim was for faculty to collectively learn with and from each other to bridge knowledge gaps around virtual learning. Overall, this novel virtual method was highly valued by participants and allowed faculty to remain connected at a time where social distancing was imperative. Lang, et al. (2020) described the work of a multiinstitutional collaboration, the Pediatric Overflow Planning - Contingency Response Network (POPCoRN). They created an inventory of high-yield topics in the form of succinct one-page living documents aimed at equipping pediatric staff and faculty to care for adult patients during 
the pandemic. This intervention proved to be extremely popular and feedback received was overwhelmingly positive regarding its real-time utility.

\section{Other or multiple areas of focus}

Nine articles $(7.1 \%)$ were difficult to categorize. Five articles focused on multiple areas and four articles categorized as "other" were diverse and did not clearly fit into another category. Iqbal et al. (2020) investigated the use of a free cloud-based App, Telegram, that allowed students to form groups or channels to facilitate sharing of educational resources, communication, collaborative learning, and wellbeing. Students found it effective, but some complained it created overload and caused distraction. Niburski and Niburski (2020) created a curated source of COVID-19 information (www.whohascoronavirus.com). The site contained a case tracker that utilized information from World Health Organization (WHO), as well as clinical information regarding treatment modalities, radiographic images, etc. collated from articles in the Journal of the American Medical Association (JAMA). Tang et al. (2020) described a self-ultrasound training program for radiology. Whilst this allowed learners to keep their scanning skills fresh, a major drawback was a lack of pathology. Gallardo et al. (2020) distributed surgical instruments to implement a home-based microsurgical skills training program for neurosurgery residents, involving low-cost items (e.g., a shoebox). Skills evaluations were conducted remotely via video.

\section{Educational or other outcomes}

Ninety-eight articles described Kirkpatrick level 1 outcomes (satisfaction or other forms of reaction. Seventy-three articles described Kirkpatrick level 2 outcomes, twenty-six discussed 
changes in attitudes (2a) and a further forty-seven changes in knowledge or skills (2b). Only two articles described Kirkpatrick level 3, changes in behavior. Seven articles reported Kirkpatrick Level 4 outcomes, with six describing changes in organizational practice and one outlining a change in clinical outcomes. Eight studies reported no Kirkpatrick outcomes. The articles reporting Kirkpatrick levels 3 and 4 were predominately works focused on simulations to care for patients with COVID-19 or clinical service reconfigurations to extend the ability to provide care during the surge. Forty-three articles reported outcomes at multiple Kirkpatrick levels. One exemplary simulation article (Cheung et al. 2020) described outcomes at all 4 levels (summarized in Figure 1 in their paper). Participants were satisfied with the training and learning objectives were met (level 1). They demonstrated learning (level 2) in the form of proper donning and doffing PPE and hazard recognition. They showed changes in behavior (level 3) related to areas of personal strength (e.g., assertiveness and self-efficacy scores). They also showed changes in organizational practice (level 4), including standardization of airway management and infection control that have resulted in zero cases of COVID amongst HCW in Hong Kong.

Other measures of effectiveness were reported in thirty articles. Such measures included quality improvement (e.g., checklist development, identification of latent safety threats leading to practice changes), policy changes, development of best practices, or other impacts (e.g., staffing to augment capacity, healthcare workforce strengthening). One remarkable example was Aluisio et al. (2020). This academic - humanitarian partnership trained > 900 trainers in core competencies to care for COVID-19 patients. These trainers went on to train $>22,000$ frontline healthcare workers HCW in low and lower-middle-income countries. 
During data extraction, we noted that outcomes were reported in varying levels of detail, with some offering more subjective findings (e.g., Amin et al. 2020, Chow et al. 2020) and others offering details and specifics (Babal et al. 2020, Shi et al. 2020, Vining et al. 2020). The reviewers noted an overall lack of consistency in reporting of Kirkpatrick's educational outcomes. Many articles described Kirkpatrick's, but they were not labelled as such. A few articles claimed Kirkpatrick levels that were not actually achieved, reflecting variable application of terminology.

\section{Discussion}

\section{Approach and methodology}

The COVID-19 pandemic has challenged the global medical education community to rapidly innovate and disseminate their work. This has created a rapidly expanding evidence base that is quite rare in education. As such, the author teams conducting this and the prior review by Gordon et al. (2020) had to embrace methodologies not common within BEME in order to ensure methods that were fit for purpose. Gordon et al. (2020) chose a rapid review approach to explore an emerging topic in a compressed timeframe (4 weeks). The current team initially planned an update review with a similar methodology, but pilot searches revealed that a very large and divergent evidence base had emerged in the ensuing months. The immediate temptation was to choose to complete one large systematic review synthesizing all literature in detail. However, this was unlikely to produce a review with much depth or utility. Thus, the team decided to conduct a scoping review to map the broad array of developments to date, to guide future research and identify areas in need of more focused systematic reviews. 
The scoping review approach offers a unique set of tools for evidence synthesis, but it must be employed for the correct purpose under the correct circumstances (Pham et al. 2014). Many scoping reviews in the field align with the rhetoric of 'scoping', but beyond use of the nomenclature, do not fully embrace the purpose or promise of such methods. For this review, the first instance of a scoping review within BEME, we wanted to map the extent, range and nature of medical education developments deployed in response to COVID-19 since the prior review. Detailed descriptions, content analyses, and quality assessments were not our purpose. Rather, we aimed to broadly chart the data, identify areas of convergence for future reviews, and more importantly, highlight areas with a paucity of outputs to guide future research.

\section{Summary of Results}

Our review showed that UME has received the most attention to date, followed by GME, then CME. Whilst the majority of interventions were implemented by academic hospitals and universities, the number of developments coordinated by national organizations, and regional, national and international collaborations (Table 3) have markedly increased since the last review (Gordon et al. 2020). As this is a global pandemic, this level of cooperation is heartening to see. These developments have shown pathways to break down historical silos in medical education, highlighting future opportunities to educate across traditional 'brick and mortar' or other boundaries. Collaborations have been effective not only in the realm of online learning (Balakrishnan et al. 2020, Beer et al. 2020, Domen et al. 2020, Duggan et al. 2020, Elledge et al. 2020, Goncalves et al. 2020, Rasouli et al. 2020, Rose et al. 2020, Thum DiCesare et al. 2020), but also in training to treat patients with COVID-19 (Aluisio et al. 2020), well-being / learner 
support (Blankenburg et al. 2020, Sockalingam et al. 2020, Steeves-Reece et al. 2020), clinical service reconfigurations (Dennis et al. 2020), and faculty development (Lang et al. 2020). Buitendijk et al. 2020 argued that COVID-19 is an opportunity to rethink global cooperation in higher education and research, noting "we need global solutions to global challenges and universities need to work harder and better at collaborating." Future research should build on work to date and augment collaborations, as a means of providing greater access to expertise, increasing equity and lessening educational disparities.

We were surprised by the distribution of developments as it related to disciplines or medical specialties (Table 4). Arguably, emergency medicine and internal medicine (particularly pulmonary critical care) have been the most "frontline" specialties during this pandemic, yet relatively few educational developments ( $n=8$ and 5, respectively) emerged from these specialties. Instead, we saw large numbers of developments published by surgery and surgical subspecialties $(n=27)$ and pathology and radiology $(n=15)$. We hypothesize that this skew may be reflective of the additional time afforded to these specialties for scholarship during the pandemic due to cancellation of elective procedures. The skew could also be explained by the urgent need within some specialties to provide alternative learning experiences, as clinical and procedural-based learning were markedly diminished (Aziz et al. 2020). We were also surprised by the relative lack of articles in core clerkship specialties like family medicine $(n=2)$ and psychiatry $(n=0)$. This gap is perhaps more surprising when one considers that these two specialties have been rapid telehealth adapters and may be best positioned to produce scholarly outputs in this area. Thus, in the future, we would recommend additional research in the 
"frontline" specialties of internal and emergency medicine, as well as call on family medicine and psychiatry educators to help lead the field in telehealth interventions.

In terms of the focus of developments (Table 5), we identified tremendous activity in the realms of pivoting to online learning ( $\mathrm{n}=58$ ) and training for treating patients with COVID-19 ( $\mathrm{n}=24)$. In the prior review by Gordon et. al (2020), pivoting to online learning and simulation were also well-represented with $n=26$ and $n=8$ primary papers, respectively. We also saw a fair number of developments in the domains of assessment $(n=11)$ and wellbeing $(n=8)$, adding to the 7 assessment papers and 2 well-being papers in the prior review. Clinical service reconfigurations were not addressed robustly in this review $(n=4)$ but were addressed slightly more in the prior review $(\mathrm{n}=6)$. Arguably, clinical service reconfigurations are of greatest importance during peak surges, both to ensure adequate staffing through horizontal deployment, as well as to ensure some providers are held in reserve and not exposed if PPE is in short supply. An important article to highlight from this review is Dennis et al. (2020). They developed the Trainee Pandemic Role Allocation Tool (TPRAT) for horizontal deployment of trainees based on skillsets (www.covidstaffing.org) which may be a valuable resource for other institutions in future surges.

\section{Future reviews indicated by findings}

This scoping review clearly demonstrates that the literature base is robust enough to support more in-depth systematic reviews. The pivot to online learning category is large enough to support at least two future reviews, one focused on undergraduates and one focused on postgraduates. A narrative review was previously conducted by Gaur et al. (2020) that focused 
exclusively on preclinical online learning in UME during COVID. Unfortunately, their review methodology was not systematic. Online learning in some form is undoubtedly here to stay, so educators must sort through the array of developments to identify what works, for whom, under what circumstances, paying particular attention to the differential impacts of synchronous, asynchronous and blended learning approaches. The simulation category is also robust enough to justify its own in-depth review in the near term. This scoping review has already identified several exemplary articles in this area: Cheung et al. (2020) achieved outcomes at all Kirkpatrick levels; Dubé et al. (2020) trained 30,000 frontline HCW in 5 weeks! We have also identified potential areas of focus for future reviews, including in-situ simulations for systems testing versus training. Assessment, wellbeing, and clinical service reconfiguration are likely to have enough articles for smaller, focused reviews.

\section{Future primary research areas indicated by findings}

Many critical areas remained under-represented in this scoping review and should be prioritised by researchers and editors in the future. Three areas are of immediate concern and warrant explicit focus, namely, telehealth, interviews and faculty development.

First, whilst the use of telehealth has surged dramatically, up $8336 \%$ in the United States at the peak according to national claims data (Fair Health 2020), few developments $(n=5)$ addressed education in telehealth. Given that telehealth is likely to persist for both safety and convenience long after the pandemic abates, studies in this domain are urgently needed. Telehealth warrants particular attention as it relates to two key educational areas: curricula and assessments (i.e., how 
can learners be educated in optimal telehealth techniques and how can educators ensure learners achieve appropriate competencies from the use of these techniques?)

Second, developments addressing interviews for admission to medical school and selection to residency are under-reported $(n=4)$. We suspect this is partly due to the timing of the application cycle and anticipate an increase in developments in the coming months. Several perspectives and society guidelines have already been published on the topic (e.g., Chou et al. 2020, Chretien et al. 2020), but due to lack of outcomes data they did not meet the inclusion criteria of our review. Of note, the last two decades have witnessed a redesign of admissions processes across the continuum, with increased emphasis on holistic reviews to minimize bias in selection. This has been accompanied by the administration of more complex assessments (e.g., multiple miniinterviews and situational judgement tests) (Dore et al. 2010, Patterson et al. 2016). How these can be practically administered during the pandemic is a pragmatic concern. There are also wider questions concerning the validity and reliability associated with such shifts to an online environment that are of equal, if not greater importance. Another concern is the potential for "over application" behavior on the part of applicants this interview season. This may stress the capacity of programs to manage the medical school admission and residency selection processes without significant innovations (Hammoud et al. 2020).

Finally, there was an almost complete lack of articles in the area of faculty development (1.6\%). This was particularly surprising given the acute need for faculty training to teach using new modalities (e.g., Zoom), as well as the urgent need to "re-train" faculty deployed to other 
services. We would strongly encourage the implementation and reporting of additional developments in this area.

\section{Evolution of studies since last review}

The growth in the literature since our previous review (Gordon et al. 2020) is quite remarkable given the addition of more stringent inclusion criteria (i.e., outcomes). However, the initial exponential growth in primary papers seems to have stopped at a steady output of $\sim 30$ papers per month. This initially seemed surprising, but upon reflection, the explanation is clear. We are witnessing a unique bottle neck effect, created by the capacity of top journals. These journals have hard limits to how many papers they are able to publish. Whilst there are options without such a bottle neck, many authors prefer to publish in traditional journals with impact factors, hence the limitation on space. This is a vital finding, as it creates a paradox for authors vying for limited space and editors peer reviewing work - every paper must count! From the perspective of secondary researchers, this is deeply problematic. If the evidence base is to grow and evolve, as indeed it should, each paper should build on the last, expanding on findings, refuting, supporting or evolving the work. With the clear identification of a bottle neck that is unlikely to change authors and editors will likely continue to focus their efforts on articles that stand alone as a high-quality pieces, rather than enriching the wider tapestry of evidence in the field, building on prior work and reviews such as this.

\section{Strengths and limitations}

This scoping review carefully adhered to the five stages outlined by Arksey and O'Malley 2005. The scoping process allowed for evolution of the inclusion criteria after an initial look at the 
literature, and we believe the addition of Kirkpatrick's and other outcomes contributed to the strength of this review. We completed the review within 8 weeks, to ensure the presentation of our findings was timely, to guide future developments and educational research. This was a remarkable feat for a review with 127 primary papers. We were able to do this and ensure rigor was not compromised, in large part due to an experienced team.

Of course, this review had several limitations. First, we limited our search to four databases to align with Gordon et al. (2020). Whilst this was consistent with practice in prior BEME reviews, we may have missed a few developments. Second, due to the accelerated time frame for this review, we did not conduct the optional sixth step for scoping reviews described by Levac et al. (2010) - consultation with stakeholders. This may have added insights beyond those in the literature. Third, we did not describe each study in detail nor conduct a thematic analysis, as that was beyond the scope of this type of review. For readers who wish to explore the studies in greater detail, Table 1 provides a searchable resource and expanded descriptions not provided in the text. Finally, unlike Gordon et al. (2020), we did not assess the quality of the study designs nor the quality of reporting. As the quality of the primary papers strongly influences the replicability of developments in other contexts, we strongly recommend that future full or focused reviews contain both types of quality assessments.

\section{Conclusions}

Institutional and regional mandates made in response to the COVID-19 pandemic have led to drastic changes in the delivery of medical education worldwide. This review collates developments through mid-September, demonstrating the extent and range of scholarly activity 
to date. We have highlighted several exemplary articles, as well as productive collaborations on which future work can build. We have noted specialties that have published more extensively (e.g., surgery and surgical sub-specialties), and called on others to do more (e.g., emergency, internal, and family medicine). We have also called attention to relative areas of strength (e.g., the pivot to online learning and simulations), as well as areas in urgent need of development (e.g., telehealth, interviews and faculty development.

It is our fervent hope, that educators and editors will use this review as a roadmap to guide future developments. We are fast approaching the one-year mark from when COVID-19 was declared a pandemic. Whilst the initial months were understandably chaotic, with educators scrambling to find any possible solution to pressing problems, we are now entering a phase of maturation. In the next phase, we must determine what works, for whom, under what circumstances, so that we can determine which interventions should remain in a post-pandemic world.

Acknowledgements: The authors would like to acknowledge the patients who have suffered from or lost their lives to COVID-19, our colleagues who have bravely battled this pandemic at great personal cost, and our learners for their resilience and adaptability in response to enormous changes in medical education. The authors would also like to thank Whitney Townsend for her expert input into the search strategy and assistance running the database search.

Declaration of Interest: The authors report no declarations of interest. 


\section{Notes on Contributors:}

(Blinded)

\section{References}

Abraham HN, Opara IN, Dwaihy RL, Acuff C, Brauer B, Nabaty R, Levine DL. 2020. Engaging third-year medical students on their internal medicine clerkship in telehealth during COVID-19. Cureus. 24;12(6):e8791. doi: 10.7759/cureus.8791.

Aluisio AR, Zhu E, Gil G, Kenyon T, Uzevski V, Levine AC. 2020. Academic-humanitarian partnerships: leveraging strengths to combat COVID-19. Glob Health Action. 13(1):1797296. doi: 10.1080/16549716.2020.1797296.

Amin HA, Shehata MH, Ahmed SA. 2020. Step-by-step guide to create competency-based assignments as an alternative for traditional summative assessment. MedEdPublish, 9(1), 120, https://doi.org/10.15694/mep.2020.000120.1

Andreae MH, Dudak A, Cherian V, Dhar P, Dalal PG, Po W, Pilipovic M, Shah B, Hazard W, Rodgers DL, Sinz EH. 2020. Healthcare simulation to prepare for the COVID-19 pandemic. J Clin Anesth. 66:109928. doi: 10.1016/j.jclinane.2020.109928. 
Andreae MH, Dudak A, Cherian V, Dhar P, Dalal PG, Po W, Pilipovic M, Shah B, Hazard W, Rodgers DL, Sinz EH. 2020. Data and debriefing observations on healthcare simulation to prepare for the COVID-19 pandemic. J Clin Anesth. 31:106028. doi: 10.1016/j.dib.2020.106028.

Ansari U, Mendonca C, Danha R, Robley R, Davies, T., 2020. The effects of personal protective equipment on airway management: An in-situ simulation. Trends Anaesth Crit Care. 34:23-7. doi: 10.1016/j.tacc.2020.07.003.

Arksey H, O'Malley L. 2005. Scoping studies: towards a methodological framework. Int J Soc Res. 8(1):19-32. doi: 10.1080/1364557032000119616

Ashton E, Skayem C, Ouazana-Vedrines C, Hamann P. 2020. Junior doctors: when fresh blood fast-tracks the fight against COVID-19. Postgrad Med J. doi: 10.1136/postgradmedj-2020138782.

Astani SA, Langroudi TF, Haghighatkhah H, Keshavarz E, Bahrami-Motlagh H, Haseli S, Bagheri AK, Taheri MS. 2020. Radiology department and residency program response and adaption to COVID 19. Acad Radiol. 27(7):1054-1055. doi: 10.1016/j.acra.2020.04.039.

Ayoub P, Chang DD, Hussein N, Stewart K, Wise A, Malik I, Robbins K, Savage B, Johnson M, Shah S. 2020. Medical student mobilization during a pandemic: The Ochsner Clinical School response to COVID-19. Ochsner J. 20(2):146-150. doi: 10.31486/toj.20.0069. 
Aziz H, James T, Remulla D, Sher L, Genyk Y, Sullivan ME, Sheikh MR. 2020. Effect of COVID-19 on surgical training across the United States: a national survey of general surgery residents. J Surg Educ. doi: 10.1016/j.surg.2020.07.037

Babal JC, Webber SA, Ruedinger E. 2020. First, do no harm: Lessons learned from a storytelling event for pediatric residents during the COVID-19 pandemic. Acad Pediatr. 20(6):761-762. doi: 10.1016/j.acap.2020.05.030.

Balakrishnan R, Singh K, Harigopal M, Fineberg S. 2020. A novel "Google Classroom" based pathology education tool for trainees during COVID-19 pandemic: Impactful learning while social distancing. Arch Pathol Lab Med. doi: 10.5858/arpa.2020-0476-LE.

Bandi F, Karligkiotis A, Mellia J, Gallo S, Turri-Zanoni M, Battaglia P, Castelnuovo P. 2020. Strategies to overcome limitations in Otolaryngology residency training during the COVID-19 pandemic. Eur Arch Otorhinolaryngol. 1-4. doi: 10.1007/s00405-020-06228-9.

Barr H, Koppel I, Reeves S, Hammick M, Freeth D. 2008. Effective interprofessional education: argument, assumption and evidence. John Wiley \& Sons.

Bautista CA, Huang I, Stebbins M, Floren LC, Wamsley M, Youmans SL, Hsia SL. Development of an interprofessional rotation for pharmacy and medical students to perform telehealth outreach to vulnerable patients in the COVID-19 pandemic. 2020. J Interprof Care. 34(5):694-697. doi: 10.1080/13561820.2020.1807920. 
Beer L, Gray M, Carbajal MM, French H, Vasquez M, Bauserman M, Bonachea EM. 2020. "Megaflip," a Novel approach to national collaboration for flipped classroom education. Acad Pediatr. 20(6):758-759. doi: 10.1016/j.acap.2020.05.027.

Bhashyam AR, Dyer GSM. 2020. "Virtual" boot camp: Orthopaedic intern education in the time of COVID-19 and beyond. J Am Acad Orthop Surg. 28(17):e735-e743. doi: 10.5435/JAAOS-D20-00559.

Blankenburg R, Poitevien P, Gonzalez Del Rey J, Degnon L, Virtual café study team. 2020. Virtual cafes: An Innovative way for rapidly disseminating educational best practices and building community during COVID-19. Acad Pediatr. 20(6):756-757. doi: 10.1016/j.acap.2020.05.025.

Bramer WM, Giustini D, de Jonge GB, Holland L, Bekhuis T. 2016. De-duplication of database search results for systematic reviews in EndNote. J Med Libr Assoc. 104(3):240-43.

Buckley H. 2020. Faculty development in the COVID-19 pandemic: So close - yet so far. Med Educ. 10.1111/medu.14250. doi: 10.1111/medu.14250. 
Buitendijk S, Ward H, Shimshon G, Sam AH, Sharma D, Harris M. 2020. COVID-19: an opportunity to rethink global cooperation in higher education and research. BMJ Glob Health. 5(7):e002790. doi:10.1136/bmjgh-2020-002790

Buléon C, Minehart RD, Fischer MO. 2020. Protecting healthcare providers from COVID-19 through a large simulation training programme. Br J Anaesth. 125(5):e418-e420. doi: 10.1016/j.bja.2020.07.044.

Burns R, Wenger J. 2020. A remotely conducted paediatric bootcamp for fourth-year medical students. Med Educ. 54(7):668-669. doi: 10.1111/medu.14187.

Byrnes YM, Civantos AM, Go BC, McWilliams TL, Rajasekaran K. 2020. Effect of the COVID19 pandemic on medical student career perceptions: a national survey study. Med Educ Online. 25(1):1798088. doi: 10.1080/10872981.2020.1798088

Carroll T, Mooney C, Horowitz R. 2020. Re-ACT: Remote advanced communication training in a time of crisis. J Pain Symptom Manage. S0885-3924(20)30691-30696. doi:

10.1016/j.jpainsymman.2020.08.013.

Chandra S, Laoteppitaks C, Mingioni N, Papanagnou D. 2020. Zooming-out COVID-19: Virtual clinical experiences in an emergency medicine clerkship. Med Educ. 10.1111/medu.14266. doi: 10.1111/medu.14266. 
Cheung VK, So EH, Ng GW, So SS, Hung JL, Chia NH. 2020. Investigating effects of healthcare simulation on personal strengths and organizational impacts for healthcare workers during COVID-19 pandemic: A cross-sectional study. Integr Med Res. 9(3):100476. doi: 10.1016/j.imr.2020.100476.

Choi B, Jegatheeswaran L, Minocha A, Alhilani M, Nakhoul M, Mutengesa E. 2020. The impact of the COVID-19 pandemic on final year medical students in the United Kingdom: a national survey. BMC Med Educ. 20(1):206. doi: 10.1186/s12909-020-02117-1

Chou DW, Pletcher SD, Bruss D, Sung CK, Diaz RC, Liang J, Durr ML. 2020. Otolaryngology Residency Interviews in a Socially Distanced World: Strategies to Recruit and Assess Applicants. Otolaryngol Head Neck Surg. 0194599820957961. doi: 10.1177/0194599820957691

Chow C, Shahdadpuri R, Kai-Qian K, Hwee CY. 2020. The next pandemic: Supporting COVID19 frontline doctors through film discussion. J Med Humanit. 41(4):585-595. doi: 10.1007/s10912-020-09662-2.

Chretien KC, Raj JM, Abraham RA, Aronowitz P, Astiz DJ, Chheda SG, Esquivel EL, Garcia MM, Ismail N, Lane S, et al. 2020. AAIM Recommendations for the 2020-2021 Internal Medicine Residency Application Cycle in Response to the COVID-19 Pandemic. Amer J Med. 133(10):1223-1226. doi: 10.1016/j.amjmed.2020.06.002 
Clark JM, Sanders S, Carter M, Honeyman D, Cleo G, Auld Y, Booth D, Condron P, Dalais C, Bateup S, et al. 2020. Improving the translation of search strategies using the Polyglot Search Translator: a randomized controlled trial. J Med Libr Assoc. 108(2):195-207.

Clemmons K, Boehme K, Cannon M, Graham J, et al. 2020. 'Building up while shutting down: An academic health system educational response to the COVID-19 pandemic. MedEdPublish. 9(1)165. https://doi.org/10.15694/mep.2020.000165.1

Co M, Chu KM. 2020. Distant surgical teaching during COVID-19 - A pilot study on final year medical students. Surg Pract. 10.1111/1744-1633.12436. doi: 10.1111/1744-1633.12436.

Coiado OC, Yodh J, Galvez R, Ahmad K. 2020. How COVID-19 Transformed Problem-Based Learning at Carle Illinois College of Medicine. Med Sci Educ. 1-2. doi: 10.1007/s40670-02001063-3.

Collado-Boira EJ, Ruiz-Palomino E, Salas-Media P, Folch-Ayora A, Muriach M, Baliño P. 2020. "The COVID-19 outbreak"-An empirical phenomenological study on perceptions and psychosocial considerations surrounding the immediate incorporation of final-year Spanish nursing and medical students into the health system. Nurse Educ Today.104504. doi:10.1016/j.nedt.2020.104504 
Colman N, Doughty C, Arnold J, Stone K, Reid J, Dalpiaz A, Hebbar KB. 2019. Simulationbased clinical systems testing for healthcare spaces: from intake through implementation. Adv Simul. 4(1):19. doi:10.1186/s41077-019-0108-7.

Conrad D, Hoffmann P, Berwanger U, Hüppe T, Volk T, Fink T. 2020. Preparing for the SARSCoV-2 pandemic: creation and implementation of new recommendations. J Anesth. 1-4. doi: 10.1007/s00540-020-02827-2.

Daly Guris RJ, Doshi A, Boyer DL, Good G, Gurnaney HG, Rosenblatt S, McGowan N, Widmeier K, Kishida M, Nadkarni V, Nishisaki A, Wolfe HA. 2020. Just-in-time simulation to guide workflow design for coronavirus disease 2019 difficult airway management. Pediatr Crit Care Med. 21(8):e485-e490. doi: 10.1097/PCC.0000000000002435.

Day RW, Taylor BM, Bednarski BK, Tzeng CD, Gershenwald JE, Lee JE, Grubbs EG. 2020. Virtual interviews for surgical training program applicants during COVID-19: Lessons learned and recommendations. Ann Surg. 272(2):e144-e147. doi: 10.1097/SLA.0000000000004064.

Dedeilia A, Sotiropoulos MG, Hanrahan JG, Janga D, Dedeilia P, Sideris M. 2020. Medical and surgical education challenges and innovations in the COVID-19 era: a systematic review. In Vivo. 34(3 Suppl):1603-11.

Dennis B, Highet A, Kendrick D, Mazer L, Loiselle S, Bandeh-Ahmadi H, Gupta T, Abbott K, Lea J, Dang T, Ramey M, George B, Terhune K. 2020. Knowing your team: Rapid assessment of 
residents and fellows for effective horizontal care delivery in emergency events. J Grad Med Educ. 12(3):272-279. doi: 10.4300/JGME-D-20-00290.1.

Dharamsi A, Hayman K, Yi S, Chow R, Yee C, Gaylord E, Tawadrous D, Chartier LB, Landes M. 2020. Enhancing departmental preparedness for COVID-19 using rapid-cycle in-situ simulation. J Hosp Infect. 105(4):604-607. doi: 10.1016/j.jhin.2020.06.020.

Díaz-Guio DA, Ricardo-Zapata A, Ospina-Velez J, Gómez-Candamil G, Mora-Martinez S, Rodriguez-Morales AJ. 2020. Cognitive load and performance of health care professionals in donning and doffing PPE before and after a simulation-based educational intervention and its implications during the COVID-19 pandemic for biosafety. Infez Med. 28(suppl 1):111-117.

Diaz MCG, Dawson K. 2020. Use of simulation to develop a COVID-19 resuscitation process in a pediatric emergency department. Am J Infect Control. 48(10):1244-1247. doi: 10.1016/j.ajic.2020.07.032.

Domen CH, Collins RL, Davis JJ. 2020. The APPCN multisite didactic initiative: Development, benefits, and challenges. Clin Neuropsychol. 1-18. doi: 10.1080/13854046.2020.1785013.

Dore KL, Kreuger S, Ladhani M, Rolfson D, Kurtz D, Kulasegaram K, Cullimore AJ, Norman GR, Eva KW, Bates S, et al. 2010. The reliability and acceptability of the multiple miniinterview as a selection instrument for postgraduate admissions. Acad Med. 85(10):S60-S63. doi: 10.1097/ACM.0b013e3181ed442b 
Dow N, Wass V, Macleod D, Muirhead L, McKeown J. 2020. 'GP Live'- recorded general practice consultations as a learning tool for junior medical students faced with the COVID-19 pandemic restrictions. Educ Prim Care. 1-5. doi: 10.1080/14739879.2020.1812440.

Dubé M, Kaba A, Cronin T, Barnes S, Fuselli T, Grant V. 2020. COVID-19 pandemic preparation: using simulation for systems-based learning to prepare the largest healthcare workforce and system in Canada. Adv Simul (Lond). 5:22. doi: 10.1186/s41077-020-00138-w.

Duggan MC, Goroncy A, Christmas C, Chippendale R. 2020. Staying afloat in the COVID-19 storm: GERIAtrics fellows learning online and together (GERI-A-FLOAT). J Am Geriatr Soc. 10.1111/jgs.16755. doi: 10.1111/jgs.16755.

Durfee SM, Goldenson RP, Gill RR, Rincon SP, Flower E, Avery LL. 2020. Medical student education roadblock due to COVID-19: Virtual radiology core clerkship to the rescue. Acad Radiol. 27(10):1461-1466. doi: 10.1016/j.acra.2020.07.020.

Elledge R, Williams R, Fowell C, Green J. 2020. Maxillofacial education in the time of COVID19: the West Midlands experience. Br J Oral Maxillofac Surg. S0266-4356(20)30373-9. doi: 10.1016/j.bjoms.2020.07.030.

Eusuf DV, England EL, Charlesworth M, Shelton CL, Thornton SJ. 2020. Maintaining education and professional development for anaesthesia trainees during the COVID-19 pandemic: the Self- 
isolAting Virtual Education (SAVEd) project. Br J Anaesth. 125(5):e432-e434. doi:

10.1016/j.bja.2020.07.046.

Evans AJ, Depeiza N, Allen SG, Fraser K, Shirley S, Chetty R. 2020. Use of whole slide imaging (WSI) for distance teaching. J Clin Pathol. jclinpath-2020-206763. doi: 10.1136/jclinpath-2020-206763.

Fair Health. 2020. Monthly Telehealth Regional Tracker. [accessed 2020 November 15]. https://www.fairhealth.org/states-by-the-numbers/telehealth

Favier V, Kimmoun A, Gatin A, Gallet P. 2020. Percutaneous tracheostomy simulation training for ENT physicians in the treatment of COVID-19-positive patients. Eur Ann Otorhinolaryngol Head Neck Dis. 137(4):333-338. doi: 10.1016/j.anorl.2020.06.002.

Flotte TR, Larkin AC, Fischer MA, Chimienti SN, DeMarco DM, Fan PY, Collins MF. 2020. Accelerated graduation and the deployment of new physicians during the COVID-19 pandemic. Acad Med. 95(10):1492-1494. doi: 10.1097/ACM.0000000000003540.

Gallardo FC, Martin C, Targa Garcia AA, Bustamante JL, Nuñez M, Feldman SE. 2020. Home program for acquisition and maintenance of microsurgical skills during the coronavirus disease 2019 outbreak. World Neurosurg. S1878-8750(20)31635-1. doi: 10.1016/j.wneu.2020.07.114. 
Garg M, Eniasivam A, Satterfield J, Norton B, Austin E, Dohan D. 2020. Rapid transition of a preclinical health systems science and social justice course to remote learning in the time of coronavirus. Med Educ Online. 25(1):1812225. doi: 10.1080/10872981.2020.1812225.

Gaur U, Majumder MA, Sa B, Sarkar S, Williams A, Singh K. 2020. Challenges and Opportunities of Preclinical Medical Education: COVID-19 Crisis and Beyond. SN Compr. Clin. Med. 2:1992-97. doi: 10.1007/s42399-020-00528-1

Geha R, Dhaliwal G. 2020. Pilot virtual clerkship curriculum during the COVID-19 pandemic: Podcasts, peers and problem-solving. Med Educ. 54(9):855-856. doi: 10.1111/medu.14246.

Glenn H. 2020 May 15. From medical school to fighting COVID-19 on the front lines at Bellevue hospital. NPR. [accessed 2020 Nov 12]. https://www.npr.org/sections/coronavirus-liveupdates/2020/05/15/853545647/from-medical-school-to-fighting-covid-19-on-the-front-lines-atbellevue-hospita

Gomez E, Azadi J, Magid D. 2020. Innovation born in isolation: Rapid transformation of an inperson medical student radiology elective to a remote learning experience during the COVID-19 pandemic. Acad Radiol. 27(9):1285-1290. doi: 10.1016/j.acra.2020.06.001.

Goncalves N, Din TF, Fagan JJ. 2020. COVID-19: UCT-Africa virtual ENT transcends academic silos through videoconferencing academic meetings and ward rounds. S Afr Med J. 110(8):12996. 
Gordon M, Daniel M, Patricio M. 2019. What do we mean by 'systematic' in health education systematic reviews and why it matters! Med Teach. 41(8):956-7. doi:

10.1080/0142159X.2018.1504164

Gordon M, Gibbs T. 2014. STORIES statement: Publication standards for healthcare education evidence synthesis. BMC Med. 12(1):143. doi: 10.1186/s12916-014-0143-0

Gordon M, Patricio M, Horne L, Muston A, Alston SR, Pammi M, Thammasitboon S, Park S, Pawlikowska T, Rees EL, et al. 2020. Developments in medical education in response to the COVID-19 pandemic: A rapid BEME systematic review: BEME Guide No. 63. Med Teach. 2020: 1-14. doi: 10.1080/0142159X2020.1807484

Gulati RR, Reid H, Gill M. 2020. Instagram for peer teaching: Opportunity and challenge. Educ Prim Care. 1-3. doi: 10.1080/14739879.2020.1811163.

Gupta N, Pandey S, Anshu A. 2020. Innovative anatomy assessment methods in COVID-19 pandemic: Statistical observations and students viewpoints. Bangladesh J Med Sci. 19:S21-S-27. https://doi.org/10.3329/bjms.v19i0.47831.

Hammick M, Dornan T, Steinert Y. 2010. Conducting a best evidence systematic review. Part 1: from idea to data coding. BEME Guide No. 13. Med Teach. 32(1):3-15. doi: $10.3109 / 01421590903414245$ 
Hammoud MM, Standiford T, Carmody JB. 2020. Potential Implications of COVID-19 for the 2020-2021 Residency Application Cycle. JAMA. doi: 10.1001/jama.2020.8911

Hannon P, Lappe K, Griffin C, Roussel D, Colbert-Getz J. 2020. An objective structured clinical examination: From examination room to Zoom breakout room. Med Educ. 54(9):861. doi: 10.1111/medu.14241.

Hodgson JC, Hagan P. 2020. Medical education adaptations during a pandemic: Transitioning to virtual student support. Med Educ. 54(7):662-663. doi: 10.1111/medu.14177.

Huang E, Pulice C, Sullivan A. 2020. Primary care mock codes during a pandemic: Interprofessional team-based emergency education while maintaining social distance. Acad Pediatr. 20(6):759-760. doi: 10.1016/j.acap.2020.05.021.

Huffman LC, Feldman HM, Hubner LM. 2020. Fellows front and center: Tele-training and telehealth. Acad Pediatr. 20(6):764-765. doi: 10.1016/j.acap.2020.05.023.

Iqbal MZ, Alradhi HI, Alhumaidi AA, Alshaikh KH, AlObaid AM, Alhashim MT, AlSheikh MH. 2020. Telegram as a tool to supplement online medical education during COVID-19 crisis. Acta Inform Med. 28(2):94-97. doi: 10.5455/aim.2020.28.94-97. 
Jack MM, Gattozzi DA, Camarata PJ, Shah KJ. 2020. Live-streaming surgery for medical student education - educational solutions in neurosurgery during the COVID-19 pandemic. J Surg Educ. S1931-7204(20)30239-7. doi: 10.1016/j.jsurg.2020.07.005.

Jarry Trujillo C, Achurra Tirado P, Escalona Vivas G, Crovari Eulufi F, Varas Cohen J. 2020. Surgical training during COVID-19: A validated solution to keep on practicing. Br J Surg. 10.1002/bjs.11923. doi: 10.1002/bjs.11923.

Jones TA, Vidal G, Taylor C. 2020. Interprofessional education during the COVID-19 pandemic: Finding the good in a bad situation. J Interprof Care. 34(5):633-646. doi: $10.1080 / 13561820.2020 .1801614$.

Joseph JP, Joseph AO, Conn G, Ahsan E, Jackson R, Kinnear J. 2020. COVID-19 pandemicmedical education adaptations: The power of students, staff and technology. Med Sci Educ. 1-2. doi: 10.1007/s40670-020-01038-4.

Jumat MR, Wong P, Foo KX, Lee ICJ, Goh SPL, Ganapathy S, Tan TY, Loh AHL, Yeo YC, Chao Y, Cheng LT, Lai SH, Goh SH, Compton S, Hwang NC. 2020. From trial to implementation, bringing team-based learning online-Duke-NUS medical school's response to the COVID-19 pandemic. Med Sci Educ. 1-6. doi: 10.1007/s40670-020-01039-3.

Juprasert JM, Gray KD, Moore MD, Obeid L, Peters AW, Fehling D, Fahey TJ 3rd, Yeo HL. 2020. Restructuring of a general surgery residency program in an epicenter of the coronavirus 
disease 2019 pandemic: Lessons from New York City. JAMA Surg. 155(9):870-875. doi: 10.1001/jamasurg.2020.3107.

Kesselman A, Lamparello NA, Malhotra A, Winokur RS, Pua BB. 2020. Endovascular simulation as a supplemental training tool during the COVID-19 national emergency. Clin Imaging. 67:72-73. doi: 10.1016/j.clinimag.2020.05.026.

Keswani A, Brooks JP, Khoury P. 2020. The Future of Telehealth in Allergy and Immunology Training. J Allergy Clin Immunol Pract. (7):2135-41. doi:10.1016/j.jaip.2020.05.009

Khalil R, Mansour AE, Fadda WA, Almisnid K, Aldamegh M, Al-Nafeesah A, Alkhalifah A, Al-Wutayd O. 2020. The sudden transition to synchronized online learning during the COVID19 pandemic in Saudi Arabia: a qualitative study exploring medical students' perspectives. BMC Med Educ. 20(1):285. doi: 10.1186/s12909-020-02208-z.

Khan JA, Kiani MRB. 2020. Impact of multi-professional simulation-based training on perceptions of safety and preparedness among health workers caring for coronavirus disease 2019 patients in Pakistan. J Educ Eval Health Prof. 17:19. doi: 10.3352/jeehp.2020.17.19.

Kirkpatrick JD, Kirkpatrick WL. 2016. Four levels of training evaluation. East Peoria (IL). Versa Press, Inc. 
Krawiec C, Myers A. 2020. Remote assessment of video-recorded oral presentations centered on a virtual case-based module: A COVID-19 feasibility study. Cureus. 12(6):e8726. doi: 10.7759/cureus.8726.

Kuo M, Poirier MV, Pettitt-Schieber B, Pujari A, Pettitt B, Alabi O, Rajani R. 2020. Efficacy of vascular virtual medical student education during the coronavirus disease 2019 pandemic. J Vasc Surg. S0741-5214(20)31912-1. doi: 10.1016/j.jvs.2020.08.028.

Lakissian Z, Sabouneh R, Zeineddine R, Fayad J, Banat R, Sharara-Chami R. 2020. In-situ simulations for COVID-19: a safety II approach towards resilient performance. Adv Simul (Lond). 5:15. doi: 10.1186/s41077-020-00137-x.

Laloo R, Giorga A, Williams A, Biyani CS, Yiasemidou M. 2020. Virtual surgical education for core surgical trainees in the Yorkshire deanery during the COVID-19 pandemic. Scott Med J. 65(4):138-143. doi: 10.1177/0036933020951927.

Lang A, Burger B, Doraiswamy V, Peterson R, Shore D, Vithalani V, Pfarr M. 2020. POPCoRN one-pagers: Educational materials for pediatric providers caring for adults. Acad Pediatr. 20(6):757-758. doi: 10.1016/j.acap.2020.05.013.

Lara S, Foster CW, Hawks M, Montgomery M. 2020. Remote assessment of clinical skills during COVID-19: A virtual, high-stakes, summative pediatric objective structured clinical examination. Acad Pediatr. 20(6):760-761. doi: 10.1016/j.acap.2020.05.029. 
Lawrence K, Hanley K, Adams J, Sartori DJ, Greene R, Zabar S. 2020. Building telemedicine capacity for trainees during the novel coronavirus outbreak: A case study and lessons learned. J Gen Intern Med. 35(9):2675-2679. doi: 10.1007/s11606-020-05979-9.

Lee ICJ, Koh H, Lai SH, Hwang NC. 2020. Academic coaching of medical students during the COVID-19 pandemic. Med Educ. doi: 10.1111/medu.14272.

Lee YM, Park H, Pyun SB, Yoon YW. 2020. Enforced format change to medical education webinar during the coronavirus disease 2019 pandemic. Korean J Med Educ. 32(2):101-102. doi: 10.3946/kjme.2020.158.

Leiberman JA, Nester T, Emrich B, Staley EM, Bourassa LA, Tsang HC. 2020. Coping with COVID-19: Emerging medical student clinical pathology education in the pacific northwest in the face of a global pandemic. Am J Clin Pathol. 1-8. doi: 10.1093/AJCP/AQAA152

Levac D, Colquhoun H, O'Brien KK. 2010. Scoping studies: advancing the methodology. Implement Sci. 5(1):69. doi: 10.1186/1748-5908-5-69

LoSavio PS, Eggerstedt M, Tajudeen BA, Papagiannopoulos P, Revenaugh PC, Batra PS, Husain I. 2020. Rapid implementation of COVID-19 tracheostomy simulation training to increase surgeon safety and confidence. Am J Otolaryngol. 41(5):102574. doi:

10.1016/j.amjoto.2020.102574. 
Maeda Y, Takeda K, Hayama M, Tsuda T, Shikina T, Nishiike S, Kawashima K, Inohara H. 2020. Experience with online lectures about endoscopic sinus surgery using a video conferencing app. Auris Nasus Larynx. S0385-8146(20)30202-9. doi: 10.1016/j.anl.2020.07.023.

Malhotra R, Gautam D, George J, Goyal D, Ansari MT. 2020. Conducting orthopaedic practical examination during the Covid-19 pandemic. J Clin Orthop Trauma. 11(Suppl 4):S448-S455. doi: 10.1016/j.jcot.2020.07.002.

Mastroianni G, Cano Busnelli VM, de Santibañes M, Huespe PE, Dietrich A, Beskow A, Pekolj J. 2020. Changing our training paradigms in general surgery residency during the covid-19 outbreak. Ann Med Surg (Lond). 59:10-13. doi: 10.1016/j.amsu.2020.08.049.

Matalon SA, Souza DAT, Gaviola GC, Silverman SG, Mayo-Smith WW, Lee LK. 2020. Trainee and attending perspectives on remote radiology readouts in the era of the COVID-19 pandemic. Acad Radiol. 27(8):1147-1153. doi: 10.1016/j.acra.2020.05.019.

McRoy C, Patel L, Gaddam DS, Rothenberg S, Herring A, Hamm J, Chelala L, Weinstein J, Smith E, Awan O. 2020. Radiology education in the time of COVID-19: A novel distance learning workstation experience for residents. Acad Radiol. 27(10):1467-1474. doi: 10.1016/j.acra.2020.08.001. 
Mohd HI, Azlan HAS, Ismail MS. 2020. The preparation, delivery and outcome of COVID-19 pandemic training program among the emergency healthcare frontliners (EHFs): The Malaysian teaching hospital experience. Med \& Health. 15(1):250-265.

https://doi.org/10.17576/MH.2020.1501.23

Mohos A, Mester L, Barabás K, Nagyvári P, Kelemen O. 2020. Orvos-beteg kommunikációs gyakorlat szimulált pácienssel a koronavírus-járvány idején. (A COVID-19-pandémia orvosszakmai kérdései) [Doctor-patient communication training with simulated patient during the coronavirus pandemic]. Orv Hetil. 161(33):1355-1362. Hungarian. doi: 10.1556/650.2020.31930.

Molina G, Mehtsun WT, Qadan M, Hause KC, Raut CP, Fairweather M. 2020. Virtual interviews for the complex general surgical oncology fellowship: The Dana-Farber/partners experience. Ann Surg Oncol. 27(9):3103-3106. doi: 10.1245/s10434-020-08778-y.

Mouli TC, Davuluri A, Vijaya S, Priyanka ADY, Mishra SK. 2020. Effectiveness of simulation based teaching of ventilatory management among non-anaesthesiology residents to manage COVID 19 pandemic - A Quasi experimental cross sectional pilot study. Indian J Anaesth. 64(Suppl 2):S136-S140. doi: 10.4103/ija.IJA_452_20.

Munshi F, Alsughayyer A, Alhaidar S, Alarfaj M. 2020. An online clinical examination for fellowship certification during the COVID-19 pandemic. Med Educ. 10.1111/medu.14267. doi: 10.1111/medu.14267. 
Naidoo N, Akhras A, Banerjee Y. 2020. Confronting the challenges of anatomy education in a competency-based medical curriculum during normal and unprecedented times (COVID-19 Pandemic): Pedagogical framework development and implementation. JMIR Med Educ. 6(2):e21701. doi: 10.2196/21701.

Nasca TJ. 2020. ACGME's Early Adaptation to the COVID-19 Pandemic: Principles and Lessons Learned. J Grad Med Educ. (3):375-8. doi: 10.4300/JGME-D-20-00302.1.

Newcomb AB, Duval M, Bachman SL, Mohess D, Dort J, Kapadia MR. 2020. Building rapport and earning the surgical patient's trust in the era of social distancing: Teaching patient-centered communication during video conference encounters to medical students. J Surg Educ. S19317204(20)30211-7. doi: 10.1016/j.jsurg.2020.06.018.

Niburski K, Niburski O. 2020. A corona virus tracker for clinicians and students: Assessing education during an evolving phenomenon. MedEdPublish, 9(1)111. https://doi.org/10.15694/mep.2020.000111.1

O'Connell A, Tomaselli PJ, Stobart-Gallagher M. 2020. Effective use of virtual gamification during COVID-19 to deliver the OB-GYN core curriculum in an emergency medicine resident conference. Cureus. 12(6):e8397. doi: 10.7759/cureus.8397. 
Parker EU, Chang O, Koch L. 2020. Remote anatomic pathology medical student education in Washington State. Am J Clin Pathol. 154(5):585-591. doi: 10.1093/ajcp/aqaa154.

Pasricha ND, Haq Z, Ahmad TR, Chan L, Redd TK, Seitzman GD, Parikh N, Kim TN, Schallhorn JM, Ramanathan S. 2020. Remote corneal suturing wet lab: Microsurgical education during the COVID-19 pandemic. J Cataract Refract Surg. 10.1097/j.jcrs.0000000000000374. doi: $10.1097 / j . j c r s .0000000000000374$.

Patel NM, Khajuria A, Khajuria A. 2020. Utility of a webinar to educate trainees on UK core surgical training (CST) selection - A cross sectional study and future implications amidst the COVID-19 pandemic. Ann Med Surg (Lond). 59:35-40. doi: 10.1016/j.amsu.2020.08.054.

Patterson F, Zibarras L, Ashworth V. 2016. Situational judgement tests in medical education and training: Research, theory and practice: AMEE Guide No. 100. Med Teach. 38(1):3-17. doi: 10.3109/0142159X.2015.1072619

Pears M, Yiasemidou M, Ismail MA, Veneziano D, Biyani CS. 2020. Role of immersive technologies in healthcare education during the COVID-19 epidemic. Scott Med J. 2020 (4):112-9. doi:10.1177/0036933020956317

Pennell CE, Kluckow H, Chen SQ, Wisely KM, Walker BL. 2020. Live-streamed ward rounds: a tool for clinical teaching during the COVID-19 pandemic. Med J Aust. 213(7):306-308.e1. doi: $10.5694 / \mathrm{mja} 2.50765$. 
Pham MT, Rajić A, Greig JD, Sargeant JM, Papadopoulos A, McEwen SA. 2014. A scoping review of scoping reviews: advancing the approach and enhancing the consistency. Res Synth Methods. 5(4):371-385. doi: 10.1002/jrsm.1123

Prasad N, Fernando S, Willey S, Davey K, Kent F, Malhotra A, Kumar A. 2020. Online interprofessional simulation for undergraduate health professional students during the COVID19 pandemic. J Interprof Care. 34(5):706-710. doi: 10.1080/13561820.2020.1811213.

Prigoff J, Hunter M, Nowygrod R. 2020. Medical student assessment in the time of COVID-19. J Surg Educ. S1931-7204(20)30274-9. doi: 10.1016/j.jsurg.2020.07.040.

PRISMA. 2015. Preferred Reporting Items for Systematic Reviews and Meta-Analyses (PRISMA). [accessed 2020 June 25]. http://prisma-statement.org/

Rasouli JJ, Shin JH, Than KD, Gibbs WN, Baum GR, Baaj AA. 2020. Virtual spine: A novel, international teleconferencing program developed to increase the accessibility of spine education during the COVID-19 pandemic. World Neurosurg. 140:e367-e372. doi: 10.1016/j.wneu.2020.05.191.

Rastegar Kazerooni A, Amini M, Tabari P, Moosavi M. 2020. Peer mentoring for medical students during the COVID-19 pandemic via a social media platform. Med Educ. 54(8):762-763. doi: $10.1111 /$ medu.14206. 
Reardon R, Beyer L, Carpenter K, Irwin M, Kester K, Laird J, Moore C, Shah P, Conrad R. 2020. Medical Student Development of K-12 Educational Resources During the COVID-19 Pandemic. Acad Pediatr. 20(6):763-4. doi:10.1016/j.acap.2020.05.022

Recht MP, Fefferman NR, Bittman ME, Dane B, Fritz J, Hoffmann JC, Hood J, Mercado CL, Mahajan S, Sheth MM. 2020. Preserving radiology resident education during the COVID-19 pandemic: The simulated daily readout. Acad Radiol. 27(8):1154-1161. doi: 10.1016/j.acra.2020.05.021.

Rose C, Mott S, Alvarez A, Lin M. 2020. Physically distant, educationally connected: Interactive conferencing in the era of COVID-19. Med Educ. 54(8):758-759. doi: 10.1111/medu.14192.

Rotoli J, Bodkin R, Pereira J, Adler D, Lou V, Moriarty J, Williams J, Nobay F. 2020. Emergency Medicine residency curricular innovations: Creating a virtual Emergency Medicine didactic conference. AEM Educ Train. 4(3):270-274. doi: 10.1002/aet2.10477.

Roy H, Ray K, Saha S, Asis Kumar G. 2020. A study on students' perceptions for online zoomapp based flipped class sessions on anatomy organised during the lockdown period of COVID19. J Clin Diag Res. 14(6):AC01-04. doi: 10.7860/JCDR/2020/44869.13797 
Sa-Couto C, Nicolau A. 2020. How to use telesimulation to reduce COVID-19 training challenges: A recipe with free online tools and a bit of imagination. MedEdPublish. 9(1)129. https://doi.org/10.15694/mep.2020.000129.1

Sam AH, Reid MD, Amin A. 2020. High-stakes, remote-access, open-book examinations. Med Educ. 54(8):767-768. doi: 10.1111/medu.14247.

Samueli B, Sror N, Jotkowitz A, Taragin B. 2020. Remote pathology education during the COVID-19 era: Crisis converted to opportunity. Ann Diagn Pathol. 49:151612. doi: 10.1016/j.anndiagpath.2020.151612.

Sandhu N, Frank J, von Eyben R, Miller J, Obeid JP, Kastelowitz N, Panjwani N, Soltys S, Bagshaw HP, Donaldson SS, Horst K, Beadle BM, Chang DT, Gibbs IC, Pollom E. 2020. Virtual radiation oncology clerkship during the COVID-19 pandemic and beyond. Int J Radiat Oncol Biol Phys. 108(2):444-451. doi: 10.1016/j.jjrobp.2020.06.050.

Shahrvini B, Baxter SL, Coffey CS, MacDonald BV, Lander L. 2020. Pre-clinical remote undergraduate medical education during the COVID-19 pandemic: A survey study. Res Sq. 1-39. doi: 10.21203/rs.3.rs-33870/v1.

Sharara-Chami R, Sabouneh R, Zeineddine R, Banat R, Fayad J, Lakissian Z. 2020. In situ simulation: An essential tool for safe preparedness for the COVID-19 pandemic. Simul Healthc. 15(5):303-309. doi: 10.1097/SIH.0000000000000504. 
Shi D, Lu H, Wang H, Bao S, Qian L, Dong X, Tao K, Xu Z. 2020. A simulation training course for family medicine residents in China managing COVID-19. Aust J Gen Pract. 49(6):364-368. doi: 10.31128/AJGP-04-20-5337.

Singh K, Chandra A, Lonergan K, Bhatt A. Using simulation to assess cardiology fellow performance of transthoracic echocardiography: Lessons for training in the COVID-19 pandemic. J Am Soc Echocardiogr. S0894-7317(20)30411-9. doi: 10.1016/j.echo.2020.06.021.

Singhi EK, Dupuis MM, Ross JA, Rieber AG, Bhadkamkar NA. 2020. Medical hematology/oncology fellows' perceptions of online medical education during the COVID-19 pandemic. J Cancer Educ. 35(5):1034-1040. doi: 10.1007/s13187-020-01863-6.

Sockalingam S, Clarkin C, Serhal E, Pereira C, Crawford A. 2020. Responding to health care professionals' mental health needs during COVID-19 through the rapid implementation of project ECHO. J Contin Educ Health Prof. 40(3):211-214. doi:

10.1097/CEH.0000000000000311.

Steehler AJ, Pettitt-Schieber B, Studer MB, Mahendran G, Pettitt BJ, Henriquez OA. 2020. Implementation and evaluation of a virtual elective in otolaryngology in the time of COVID-19. Otolaryngol Head Neck Surg. 194599820951150. doi: 10.1177/0194599820951150. 
Steeves-Reece AL, Elder NC, Graham TA, Wolf ML, Stock I, Davis MM, Stock RD. 2020. Rapid deployment of a statewide COVID-19 ECHO program for frontline clinicians: Early results and lessons learned. J Rural Health. 10.1111/jrh.12462. doi: 10.1111/jrh.12462.

Sud R, Sharma P, Budhwar V, Khanduja S. 2020. Undergraduate ophthalmology teaching in COVID-19 times: Students' perspective and feedback. Indian J Ophthalmol. 68(7):1490-1491. doi: 10.4103/ijo.IJO_1689_20.

Suppan L, Abbas M, Stuby L, Cottet P, Larribau R, Golay E, Iten A, Harbarth S, Gartner B, Suppan M. 2020. Effect of an e-learning module on personal protective equipment proficiency among prehospital personnel: Web-based randomized controlled trial. J Med Internet Res. 22(8):e21265. doi: 10.2196/21265.

Tan W, Ye Y, Yang Y, Chen Z, Yang X, Zhu C, Chen D, Tan J, Zhen C. 2020. Whole-process emergency training of personal protective equipment helps healthcare workers against COVID19: Design and effect. J Occup Environ Med. 62(6):420-423. doi: 10.1097/JOM.0000000000001877.

Tang PH, Chen EMH, Liang MM, Teo SY, Ong CL. 2020. Maintaining training with selfultrasound during COVID-19. Acad Radiol. 27(10):1491. doi: 10.1016/j.acra.2020.07.003. 
Tang PY, New LM, Leow WQ. 2020. Zooming for cells: Tele-education of histopathology residents during the COVID-19 pandemic. Proc Sing Healthc. doi: $10.1177 \% 2 F 2010105820944447$.

Thum DiCesare JA, Segar DJ, Donoho D, Radwanski R, Zada G, Yang I. 2020. Democratizing access to neurosurgical medical education: National efforts in a medical student training camp during coronavirus disease 2019. World Neurosurg. S1878-8750(20)31867-2. doi: 10.1016/j.wneu.2020.08.100.

Tsang ACO, Lee PP, Chen JY, Leung GKK. 2020. From bedside to webside: A neurological clinical teaching experience. Med Educ. 54(7):660. doi: 10.1111/medu.14175.

Verma A, Verma S, Garg P, Godara R. 2020. Online teaching during COVID-19: Perception of medical undergraduate students. Indian J Surg. 1-2. doi: 10.1007/s12262-020-02487-2.

Vining CC, Eng OS, Hogg ME, Schuitevoerder D, Silverman RS, Yao KA, Winchester DJ, Roggin KK, Talamonti MS, Posner MC, Turaga KK, Tseng J. 2020. Virtual surgical fellowship recruitment during COVID-19 and its implications for resident/fellow recruitment in the future. Ann Surg Oncol. 1-5. doi: 10.1245/s10434-020-08623-2.

Wenlock RD, Arnold A, Patel H, Kirtchuk D. 2020. Low-fidelity simulation of medical emergency and cardiac arrest responses in a suspected COVID-19 patient - an interim report. Clin Med (Lond). 20(4):e66-e71. doi: 10.7861/clinmed.2020-0142. 
Wlodarczyk JR, Alicuben ET, Hawley L, Sullivan M, Ault GT, Inaba K. 2020. Development and emergency implementation of an online surgical education curriculum for a General Surgery program during a global pandemic: The University of Southern California experience. Am J Surg. S0002-9610(20)30537-7. doi: 10.1016/j.amjsurg.2020.08.045.

Xu L, Ambinder D, Kang J, Faris S, Scarpato K, Moy L, Kobashi K, Lemack G, Malik R. 2020. Virtual grand rounds as a novel means for applicants and programs to connect in the era of COVID-19. Am J Surg. S0002-9610(20)30536-5. doi: 10.1016/j.amjsurg.2020.08.044.

Zhang Q, He YJ, Zhu YH, Dai MC, Pan MM, Wu JQ, Zhang X, Gu YE, Wang FF, Xu XR, Qu F. 2020. The evaluation of online course of Traditional Chinese Medicine for MBBS international students during the COVID-19 epidemic period. Integr Med Res. 9(3):100449. doi: 10.1016/j.imr.2020.100449. 